\title{
THE FASHION WINDOW: A CONCEPTUAL ANALYSIS OF DEPARTMENT STORE HOLIDAY WINDOWS
}

By

McKenzie Bohn, Bachelor of Arts, University of Lethbridge 2016

\author{
A MRP presented to Ryerson University \\ In partial fufillment of the \\ requirements for the degree of \\ Master of Arts \\ In the program of \\ Fashion Studies
}

Toronto, Ontario, Canada, 2019.

(C) McKenzie Bohn, 2019 


\section{AUTHOR'S DECLARATION FOR ELECTRONIC SUBMISSION OF A MRP}

I hereby declare that I am the sole author of this MRP. This is a true copy of the MRP, including any required final revisions.

I authorizing Ryerson University of lend this MRP to other institutions or individuals for the purpose of scholarly research.

I further authorize Ryerson University to reproduce this MRP by photocopying or by other means, in total or in part, at the request of other institutions or individuals for the purpose of scholarly research.

I understand that my MRP may be electronically available to the public. 


\begin{abstract}
The Fashion Window: A Conceptual Analysis of Department Store Holiday Windows Master of Arts in Fashion, 2019

McKenzie Bohn

Ryerson University

Window displays in the fashion industry are unique sites of meaning that combine advertising and artwork in a three-dimensional space. The current body of research surrounding window displays approaches the subject from a marketer's position and attempts to evaluate performance. This project shifts the focus to the artistic qualities of window displays as they are used by fashion retailers. The primary theoretical lens is gestalt theory, which has applications in both psychology and design. The specific windows examined are the Christmas windows at retailer Saks Fifth Avenue Toronto in December of 2018. An autoethnographic research design is employed, resulting in an exploratory empirical analysis that serves as an entry into an under-represented area of study: the fashion window as an art object. The key findings of the project are the application of gestalt theory to the design of the windows and the researcher's observations to suggest an explanation of the public's response to the displays.
\end{abstract}




\section{ACKNOWLEDGEMENTS}

This project would not have been possible without the guidance and support of Professor Robert Ott. As a supervisor, he was unfailingly supportive and consistently encouraged me to take my research into new and further directions. I cannot thank him enough for his time and insight. I extend this appreciation to Professor Osmud Rahman, my second reader, as well. I must also thank the Ryerson University School of Fashion and its wonderful faculty for creating a vibrant academic environment and continually illuminating the importance of fashion studies. Finally, I would like to thank my family, for supporting my pursuit of this goal and for sustaining me throughout. Thank you! 


\section{TABLE OF CONTENTS}

AUTHOR'S DECLARATION

ABSTRACT

ACKNOWLEDGEMENTS

LIST OF FIGURES

CHAPTER ONE: INTRODUCTION

What Is A Window Display?

Writing Approach 3

CHAPTER TWO: LITERATURE REVIEW 6

Psychology: Gestalt Theory and the Role of the Consumer 6

Fashion Windows and the Principles of their Design 10

Gestalt as a Design Theory 11

Visual Theoretical Frameworks $\quad 18$

The Retail Environment $\quad 20$

Saks Fifth Avenue and Luxury Shopping $\quad 23$

Holiday Window Displays $\quad 26$

Methods of Engagement with Window Displays 27

Non-Academic Sources of Information 30

CHAPTER THREE: METHODOLOGY 33

Introduction and Research Question 33

Research Design $\quad 33$

Fieldwork: Reflections on the Field 37

The Role of the Researcher $\quad 39$

Data Analysis Process: Coding 43

Approach to Writing the Analysis 46

CHAPTER FOUR: FINDINGS AND ANALYSIS 49

Introduction to the Analysis $\quad 49$

Analysis of Saks Fifth Avenue Christmas Window Displays 49

Analysis of the Environmental Context

Implications of Viewer Demographics $\quad 61$

Gender's Impact on Response $\quad 62$

Impact of Viewer's Age on Response $\quad 65$

Impact of Group Composition on Response 66

Engaging with Fashion Windows via Gestalt Theory $\quad 67$

$\begin{array}{ll}\text { Concluding Thoughts } & 71\end{array}$

CHAPTER FIVE: CONCLUSION

Summary of Conceptual and Methodological Frameworks $\quad 73$

$\begin{array}{ll}\text { Contributions to the Field } & 74\end{array}$

Implications for Future Research $\quad 75$

$\begin{array}{ll}\text { BIBLIOGRAPHY } & 78\end{array}$ 


\section{LIST OF FIGURES}

Figure 1. Sofia Coppola for Louis Vuitton at Le Bon Marche Riveau Gauche, 2014. "Sofia Coppola for Louis Vuitton", BWD, thebwd.com/louis-vuitton-X-sofia-coppola-springsummer-2014-fantasywindow-displays/

Figure 2. Gucci Garden windows at Harrods in London, 2017. "Gucci Garden.” Harrods Media, Harrods, www.harrods-media.com/campaigns/news/368.

Figure 3. Louis Vuitton windows at the Bond Street, London store, 2010. "Louis Vuitton: Ostrich New Bond Street London.” Chameleon, Chameleon Visual, 31 Aug 2010, chameleonvisual.co.uk/louisvuitton-ostrich-new-bond-street-london/.

Figure 4. Hermes windows in Ginza, Tokyo, 2016. "Window Display by Isabelle Daeron." Isabelle Daëron Floods Hermès Ginza Store Windows with a Wave of Water, Designboom, www.designboom.com/art/isabelle-daeron-window-display-maison-hermes-ginza-tokyo-makingwaves-06-15-2016/.

Figure 5. An example of the gestalt principle of figure \& ground; notice how you can simultaneously see a candlestick/vase in the center of the image, in white, as well as two faces in profile, in black. "Figure/Ground." The Designer's Guide to Gestalt Theory, Creative Bloq, www.creativebloq.com/graphic-design/gestalt-theory-10134960.

Figure 6. Louis Vuitton windows at a Paris, France store, 2012. “Circus Windows." Louis Vuitton Circus Windows, Paris, Retail Design Blog, retaildesignblog.net/2012/01/13/louis-vuitton-circus-windowsparis/.

Figure 7. Christmas window display at Tiffany \& Co in New York City, 2018. "NEW YORK: Tiffany \& Co." International Christmas Windows 2018, VM Plus, www.vmplus.com.au/internationalchristmas-windows-2018/.

Figure 8. Park \& Jaworski's Zones of Engagement. Atwal, G., \& Williams, A. (2009). "Luxury Brand Marketing — The Experience is Everything!" Journal of Brand Management, 16, 338-346

Figure 9. The location of Saks Fifth Avenue Toronto and the fieldwork site.

Figure 10. "Window 5" Of Theatre of Dreams, Saks Fifth Avenue Toronto 2018

Figure 11. "Window 6" Of Theater of Dreams, Saks Fifth Avenue Toronto 2018

Figure 12. "Window 7" of Theatre of Dreams, Saks Fifth Avenue Toronto 2018.

Figure 13. "Window 8" of Theatre of Dreams, Saks Fifth Avenue Toronto 2018.

Figure 14. "Window 9" of Theatre of Dreams, Saks Fifth Avenue Toronto 2018. 


\section{CHAPTER ONE: INTRODUCTION}

\section{What Is A Window Display?}

For the purposes of this project, I suggest the following as a basic definition of the window display: a window display is a small area, positioned on the street-facing side of a business, that contains items available for purchase. What purpose the window display serves, and what types of items it contains, will vary based on the type of business and its goals. The surface-level function of a window display is to visually present items available for sale within the represented business. Before the turn of the century, this was the way most business employed their front window space (if they used it for display at all; some used the space for storage, instead). Mandel's and the Marshall Field Company, two Chicago-based department stores. were among the first stores to find success by focusing on improving their window displays in the 1890s (Twyman, 1954). Today, almost every type of brick-and-mortar business, fashion retail or otherwise, employs some type of window display.

Fashion retailers were amongst the first to embrace and attempt to elevate the window display (Twyman, 1954), and I am of the opinion that the fashion window display occupies a category all its own. Some fashion retail stores employ their window space as a way of simply laying out goods for sale without much manipulation in the way of styling, but many have caught on to the potential of a window display as a marketing tool with implications beyond this exchange of purely functional information. Those who choose to employ a level of artistry and decoration in constructing their window displays communicate with viewers - all of whom are potential customers, now or in the future- 
on another level. These stores can communicate information about their brand, or their 'personality', through their styling and design choices (Martineau, 2002).

A certain degree of spectacle is generally helpful in this case. Arthur Fraser, the 'window trimmer' for Marshall Field from 1895 onwards, would change his displays on Sundays when curtains were drawn over the windows for religious observance. He would then reveal his new displays "like the opening of a new show" (Twyman, 1954). Fraser was one of the first professional window dressers to consider the window as a space for artistic expression as well as a space for commercial advertisement. He often designed the store's multiple windows around a central theme such as a specific colour (Twyman, 1954), and as such was among the first to approach window dressing as an artistic endeavor.

L. Frank Baum is best-known as the author of "The Wonderful Wizard of Oz", but prior to its publishing in 1900 he made his living as the editor of The Show Window, a journal devoted to show window display. In an 1897 piece titled "The Window Gazer", Baum recounted a conversation he had with the proprietor of D.W. Blank \& Co. The man in question had posted an ad seeking 'window gazers'; people who would be paid to stand outside his store's windows and drum up interest. The technique involved "[coming] down the street at a swinging pace, [glancing] casually at the window, and then abruptly [stopping] to gaze eagerly at the good displayed" (Baum, 1897, p. 1). A crowd would tend to accumulate around the gazer before dissipating, upon which he would walk a short distance away and then repeat the exercise. Baum asked Blank directly if he felt this was an appropriate use of his advertising dollars, and he felt quite 
sure that the presence of a window gazer helped set his windows apart from the other, "equally attractive" windows on the street (Baum, 1897, p.1).

As the practice of employing windows as a space for three-dimensional advertising has taken off, so has its artistry. Some prolific window dressers are considered artists in their own right. Simon Doonan's autobiography Confessions of a Window Dresser reveals that his approach to designing the windows for Barney's department store was very much that of an artist, and he has enjoyed renown for his designs. This brings me to qualify why I feel that window displays are a topic deserving of a more humanities-based analysis. Much of the current research available regarding window displays consists of business-focused, quantitative analysis which focuses on the window display as a tool. These studies measure statistics such as how the number of items in a window, or the frequency with which the display is changed, can affect the efficacy of the display. These studies are interesting, but I believe there is a case to be made for examining the artistic qualities of the displays as well, examining them as pieces of material culture. My suggestion is that as our practices concerning fashion retailing change, so too should the research regarding it. Research on window displays, while not prolific to begin with, has fallen out of step with the current practice. There is a need for a different type of research to begin to fill the gap that has been left by this evolution.

\section{Writing Approach}

This research project opens with a review and discussion of the current body of window display research. There are several reasons why the literature review precedes the analysis and methodology. Firstly, in looking at what types of research already exist 
on this subject, it becomes easy to see which areas have received fewer contributions. In the case of window displays, the prevalence of quantitative, marketing-focused research made it clear that there was space for more conceptual, qualitative, humanities-based studies. This is explored in greater depth within the literature review. The second purpose of the literature review is to introduce the theories that will form the lens through which this conceptual analysis will occur. This project necessitates that some of these theories be used in ways that are outside the scope of their usual applications. The second chapter provides justification as to why they have been chosen for this project and how they will fit within the context of window display analysis. Because the research body on window displays is not particularly broad, there are also several non-scholarly works that are addressed within the literature review. The purpose of their inclusion is to provide an alternate authorial point of view, and as such, they are addressed only thematically and separately from the academic sources. One of the primary goals of this research project is to fill a qualitative research gap. Therefore, it is appropriate to first establish the field as it currently exists in order to better position this project within it.

Following the literature review is an in-depth explanation of how the research project was carried out. In the methodology chapter, the autoethnographic approach that I employed is prefaced with an exploration of ethnographic research design: its strengths as a research method, the ways in which it is most commonly used and the accompanying stylistic and methodological conventions, and the ways in which the research design for this project deviate from some of these conventions. This includes a discussion of the differences between ethnography and autoethnography. Also included within the methodology chapter is a dissection of the coding process that I applied to the data that 
came out of my fieldwork. There are many different strategies for coding. Which strategy a researcher chooses is largely dependent on the genre of their research and the types of data they have collected. Since there is so much variability to the coding process, it is important to explain one's approach, and I have endeavored to do so in this section of the chapter.

The fourth chapter consists of the findings and analysis. The chapter is written in a reflective and personal style, as it consists of an extrapolation of the data collected during fieldwork via my application of the theoretical framework. This interpretation is exploratory, and as a result, the contributions of this MRP are entirely empirical. This chapter is divided into three major sections which are further subdivided according to an organizational system derived from the data coding process: 'People', 'Environment', and 'Methods of Engagement', which covers the actions taken by the public in reaction to the window displays.

The concluding chapter re-examines the conceptual and methodological frameworks in light of the findings. This chapter also covers the MRP's contributions to the field of window display research and ethnographic research, as well as implications for future research. 


\section{CHAPTER TWO: LITERATURE REVIEW}

Part of what makes window displays an interesting subject for research is the fact that there is a robust catalog of non-academic writing from experts in the field in addition to the body of academic research. Because the greater part of the academic writing regarding window displays does not deal with them conceptually, as I am aiming to, these non-academic sources have some valuable insights that helped to inform my understanding of some of the more artistic qualities of window displays. As such, I have elected to include an overview of these sources within the literature review, but will treat them separately from the peer-reviewed articles and monographs that informed my research.

\section{Psychology: Gestalt Theory and the Role of the Consumer}

To try and understand what may be happening in viewers' minds as they observed window displays without speaking with them, I turned towards the field of psychology, both specifically in regards to consumption practices and more generally to account for the non-commercial aspects of window displays that I am taking into account. I reviewed several different theoretical frameworks while deciding which would be best suited for my analysis, and eventually landed on gestalt theory as my primary lens. Gestalt theory was developed in the early twentieth-century by the theorists Kurt Koffka, Max Wertheimer, and Wolfgang Kohler. The theory was originally psychological in nature, and was defined by Koffka as an organized whole that is other than the sum of its parts (1940). A slightly mis-translated version of this definition that states that the whole is more than the sum of its parts is often used-while these definitions may appear the same 
upon first reading, there is an important distinction. Koffka's original definition suggests that the whole has an entirely separate existence from its components, while the mistranslation implies an additive effect: the whole is composed of its parts, plus something else. At the time, the theory was a rejection of the prevailing structuralist idea that complex perceptions could be best understood by breaking an experience down into its simplest components (Moore \& Fitz, 1993). According to gestalt psychologists, when perception occurs, the human mind receives various stimuli and self-organizes them into a whole, or a gestalt, that has its own reality, independent of its parts. It is not that the whole is determined by its parts, but rather, the other way around (Arnheim, 1988). Wertheimer explained the 'formula' of gestalt thusly: "there are wholes, the behavior of which is not determined by that of the individual elements, but where the part-processes are themselves determined by the intrinsic nature of the whole. It is the hope of gestalt theory to determine the nature of such wholes." $(1939$, p. 2)

A more modern interpretation of the role of gestalt in everyday life comes from Dan Ariely and Ziv Carmon, who applied gestalt to experience production and retention. They assigned the term "gestalt characteristics" to the defining features of an experience - any experience, including common ones such as "a bus ride, a meal, [or] a college course" (2000, p. 191). An experience, they explain, unfolds over time through a stream of different of different states that may vary in intensity or emotion from moment to moment. An "experience profile" is created from these varying states, but it is not simply a summary or combination of the intensity of all of these various states. Rather, a few defining features - termed gestalt characteristics — are extracted and combined to form the evaluation. The experience profile's overall "goodness" or "badness" is called 
upon when the individual in question must make a related decision (for instance, whether or not to repeat said experience) later on. The implications of the experience profile also go beyond decision making. There are hedonic consequences as well. Prospective summary assessment of an experience can evoke sensations such as anticipation and dread before the experience ever takes place, and retrospective summary evaluations influence the utility that can be derived from consuming memories after the experience occurs. I theorize that connecting with the salient characteristics of memory in this way is what enables a very effective window display to capture the consumer.

The current body of research regarding window display, which I explore further in a subsequent section, considers the consumer in regards to their purchasing behavior (that is, whether or not the display was "successful" in motivation them to enter the store and make a purchase or not). What is not considered as fully is the experience of the consumer as they view the window. This is where I see an opportunity for crossover between consumer behavior research, particularly regarding the concept of self-image (Park, Jaworski \& McInnis, 1986; Sirgy, 1982; Nicosia \& Mayer, 1976; Crowley, 1993; Laverie, Klein \& Klein, 2002; Oh \& Petrie, 2012; Lange, Rosengram \& Blom, 2016; Sen, Block \& Chandran, 2002), and window displays. Examining the field of consumer research supplies concepts such as brand-concept management (Park, Jaworski \& McInnis, 1986) that are very relevant to a comprehensive analysis of window displays. For example, Sen et al's research on consumer shopping decisions presents two research questions: are consumers' shopping decisions related in any way to their propensities to look at window displays for different types of information, and does this relationship depend on consumers' knowledge of retailer's merchandise? (2002). These objectives are 
not unlike my own, although their point of interaction with the consumer preempts mine. They seek to know what types of information the consumer brings to their windowviewing experience, while I chose to observe what kind of information the window imparts on the consumers during their viewing. They, too, identified a gap in windowfocused research, writing: "to our knowledge, no research has examined whether, how, and for whom window displays work" (Sen et al., 2002, p. 277).

Reviewing research reveals that there are different approaches to the study of consumer behavior. The concept of self-image is one such approach, with particularly strong implications for window display design. The concept of "self-image" has been used by multiple researchers to refer to subtly different phenomenon; some have observed it as a singular variable, while others consider it a marriage between multiple variables. Investigators who consider it as a single variable treat it as the actual perception of oneself; terms for this include "actual self", "real self", "basic self", "extant self", or simply, "self" (Sirgy, 1982). Those of the belief that self-concept has more than one component recognize two parts; the actual self-image (as described previously) and the ideal self-concept, defined as the image of oneself as one would like to be (Sirgy, 1982). It is in the ideal self-concept that I see a relationship with window displays. I believe that the intent of a window display is to connect with this ideal self-concept, either by convincing a viewer that the shop's wares will allow them to come in line with their ideal self-concept, or for those who already feel as if they have already achieved their ideal self-concept, that the shop's wares are meant for them.

In conclusion, I have pulled together research from several different fields in order to gain a kind of understanding about the thoughts and feelings of viewers 
observing a window display. Research on consumer psychology provides insight on the way that the commercial aspects of a window may influence viewer's perception, while gestalt theory and self-concept provide additional context to account for the myriad, noncommercial functions of a display window.

\section{Fashion Windows and the Principles of their Design}

One of the strengths of gestalt theory is that its basic principles are very versatile; while the theory's roots are in psychology, it has since found wider applications that make it equally as valuable for analyzing the design of a window display and its relationship with its surroundings, as it is for analyzing its viewers. Graphic designers, for instance, often employ the laws of gestalt in print design. Max Wertheimer's 1939 essay "Laws of Organization in Perceptual Forms" was perhaps the first to apply gestalt to simple graphic illustrations of dots and lines. In the essay, Wertheimer concluded that humans have an innate tendency to consider elements as belonging together if they look alike, are near to each other, or have structural economy (Wertheimer, 1939). Wertheimer's theories were themselves born from the German concept of praganz, or the clearcutness or pithiness of visual forms (Verstegen, 2005). Praganz states that, given a visual stimulus, we tend to organize it in the simplest way possible. Roy Behrens provided a more modern take on the role of gestalt in graphic design in his article "Art, Design, and Gestalt Theory" (1998), where he built upon the extremely simple forms laid out by Wertheimer to demonstrate how the same principles are equally applicable in modern (for 1998) logo and print design.

Gestalt theory for design usually suggests six principles, which are commonly agreed upon as being: similarity, continuation, closure, proximity, figure and ground, and 
symmetry. In reviewing the research concerning gestalt applications in two-dimensional design, I hope to find ways that gestalt can also be applied to three-dimensional design. This will reinforce the positioning of fashion windows as a site of artistic intention and meaning.

\section{Gestalt as a Design Theory}

The six principles of gestalt, as generally recognized, are: similarity, continuity, closure, proximity, figure and ground, and symmetry (Wong, 2010). The guidelines provided by these principles are not intended to evaluate the artistic intention or creative merit of a design. Rather, they are tools that a designer can employ in order to maximize the clarity and communicative potential of the design. It is important to recognize that these principles provide guidelines for designers, rather than strict rules. Designers should keep the principles in mind, but may choose to emphasize one or two over the others for effect. Because the primary purpose of a fashion window is to catch customers' attention and provide enough information to instigate further investigation, it does not necessarily benefit window dressers to create confusing, obtuse displays. As such, the principles of gestalt design are highly relevant for the preparation of a fashion window.

The principle of similarity suggests that when faced with a grouping of objects that are very similar in size, shape, colour, or texture, viewers will tend to visually group these objects (Wong, 2010). This can be used to create a larger picture out of many smaller elements, or it can be used to focus attention on a disparate object that does not share the characteristics of the others. These different strategies are illustrated well in the Sofia Coppola for Louis Vuitton windows, shown in Figure 1, and Gucci Garden windows, shown in Figure 2. 


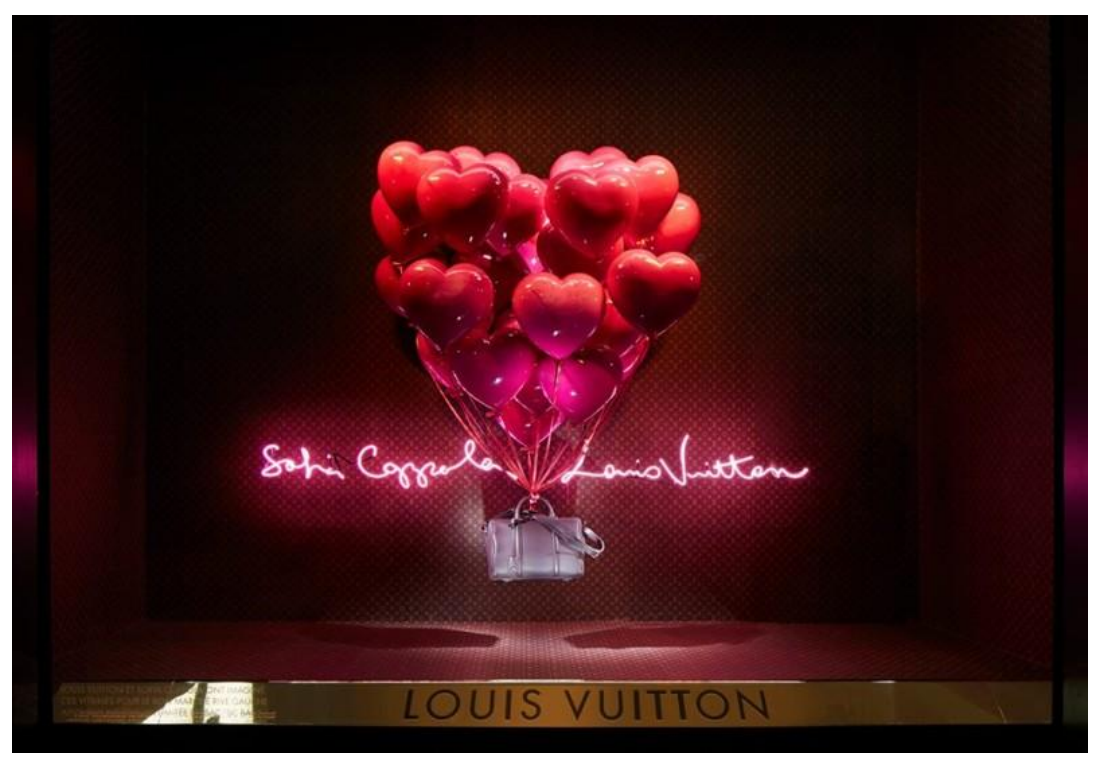

Figure 1. Sofia Coppola for Louis Vuitton at Le Bon Marche Riveau Gauche, 2014. "Sofia Coppola for Louis Vuitton", BWD, thebwd.com/louis-vuitton-x-sofia-coppola-springsummer-2014-fantasy-windowdisplays/

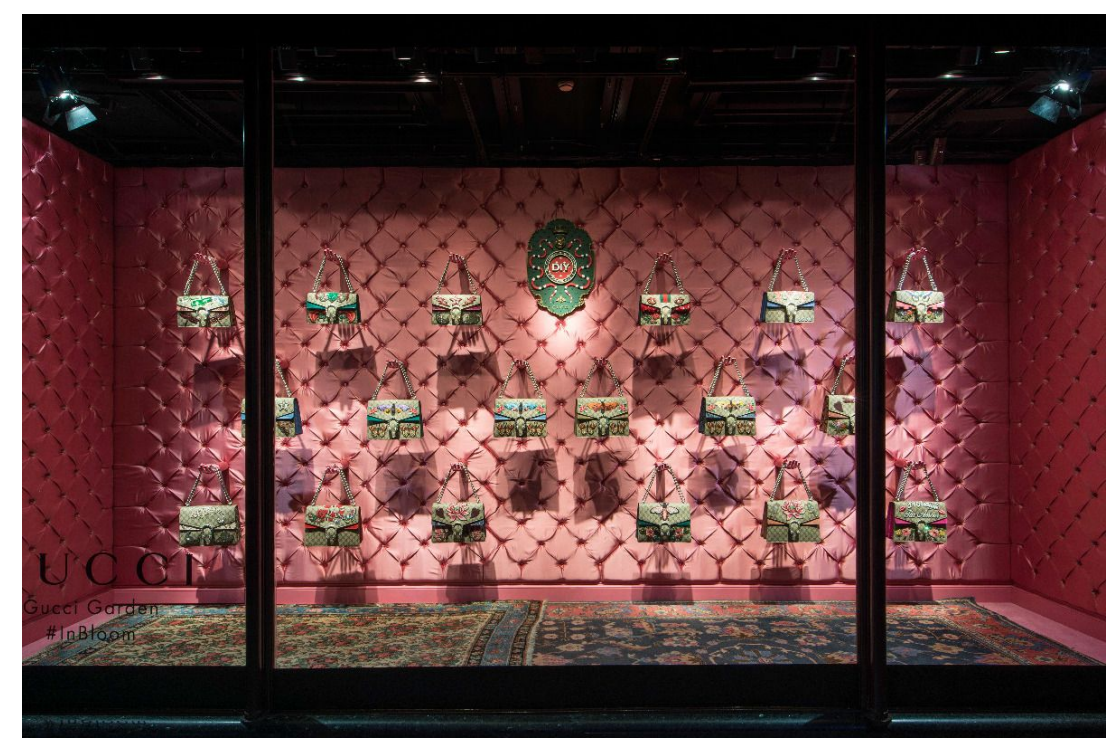

Figure 2. Gucci Garden windows at Harrods in London, 2017. "Gucci Garden.” Harrods Media, Harrods, www.harrods-media.com/campaigns/news/368.

Including many identical heart-shaped balloons above a solitary handbag in the Louis Vuitton window draws the eye towards the bag, especially because there aren't many other elements in the display. In contrast, the Gucci window features eighteen 
symmetrically-arranged Gucci handbags. The bags are technically different, but are nonetheless very similar in style. The result of this is good visual impact overall, but no one bag is featured. The disparate element in this case is the green crest advertising Gucci's DIY service, which allows customers to embellish their purchases with various patches and other decorative elements in-store. One of these windows is not necessarily more successful than the other; the Louis Vuitton windows were designed to advertise a specific collection, so highlighting just one item from the collection was a more effective choice. In contrast, the Gucci windows serve the more general purpose of advertising the brand and its available services, and so there was no need to put any one item at the forefront.

Continuation is the principle through which a viewer's eye is drawn along a path; we prefer to see a continuous figure, rather than separate parts, and as a result will often mentally complete a path even if there are gaps (Wong, 2010). The Louis Vuitton Bond Street Fall/Winter 2010 windows, shown in Figure 3, utilized this principle in a simple but effective way. A long-necked ostrich spans two neighboring windows, with the neck attached to the body in the left window and stretching across to the head in the right. The windows are fully separate, but the principle of continuation encourages us to see them as connected by the neck of the ostrich. In this way, the designers have gotten around the limitations of the physical window space. 


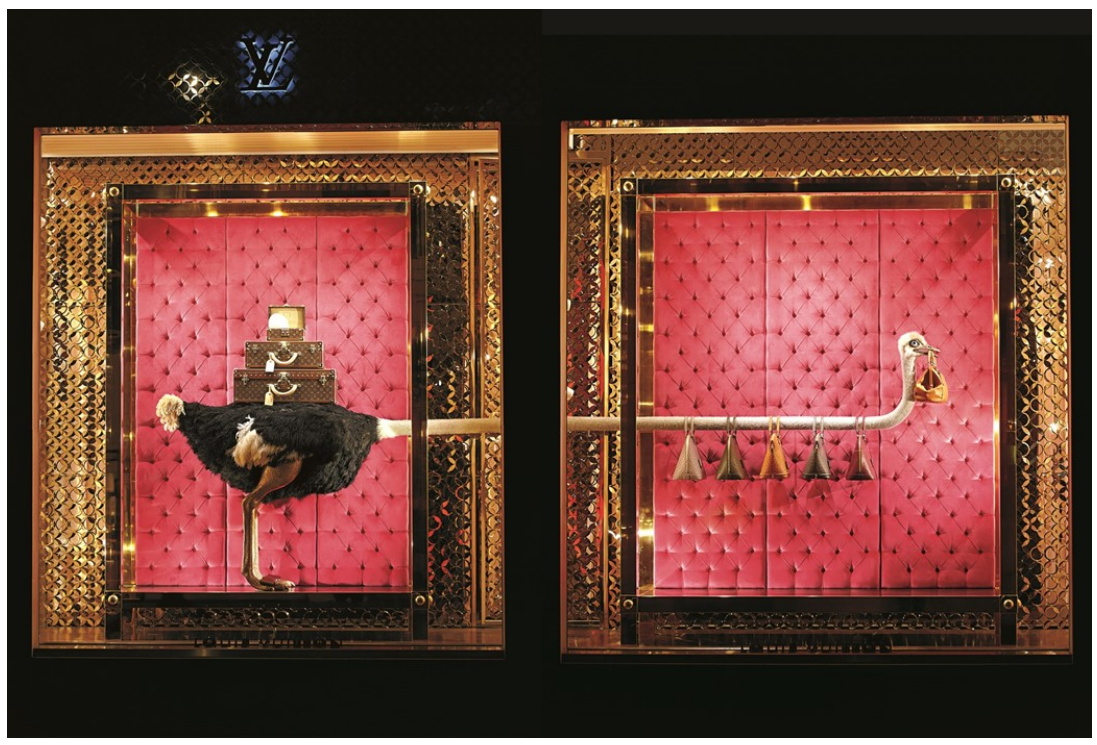

Figure 3. Louis Vuitton windows at the Bond Street, London store, 2010. "Louis Vuitton: Ostrich New Bond Street London." Chameleon, Chameleon Visual, 31 Aug 2010, chameleonvisual.co.uk/louis-vuittonostrich-new-bond-street-london/.

The principle of closure also draws upon the tendency of the human eye to see complete shapes. Continuation applies primarily to lines and curves, while closure applies the same concept to shapes that are either incomplete or have large, open interior spaces. Stencilled artwork is a good example of the principle of closure - the medium necessitates that the form of the shape be broken up, but viewers can almost always recognize the shape.

Proximity uses the close arrangement of objects in order to create a group association between them (Wong, 2010). This is also exemplified in the Sofia Coppola for Louis Vuitton windows (Figure 1) — because of the way they are arranged, the heartshaped balloons register as one large heart to the viewer, especially from a distance. The 2016 Spring/Summer Hermes windows in Ginza, Tokyo's upscale shopping district, are another great example of proximity in design, shown in Figure 4. In this instance, many 
individual water-droplet shapes are arranged to form a splashing puddle in one window, and a wave in another.

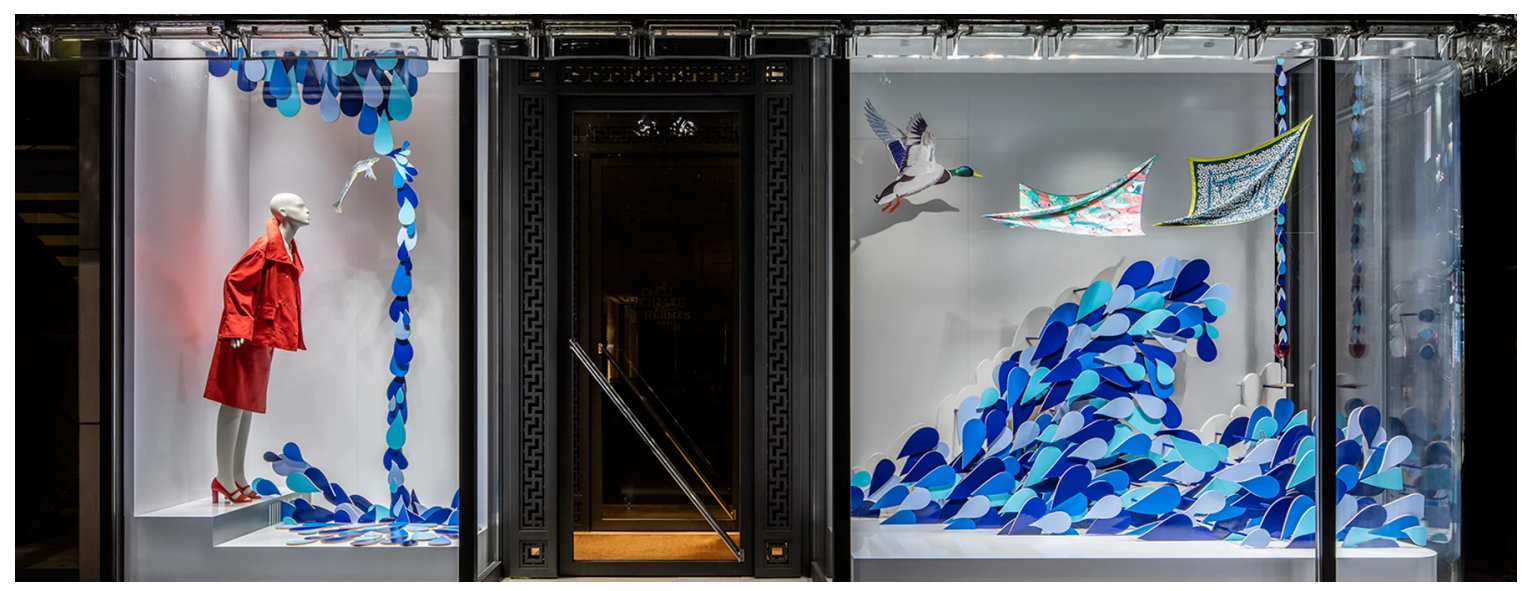

Figure 4. Hermes windows in Ginza, Tokyo, 2016. "Window Display by Isabelle Daeron." Isabelle Daëron Floods Hermès Ginza Store Windows with a Wave of Water, Designboom,

www.designboom.com/art/isabelle-daeron-window-display-maison-hermes-ginza-tokyo-making-waves-06$15-2016 /$.

Figure and ground, as design principles, are more challenging to implement in three dimensions. This principle describes the eye's tendency to see and separate objects from their surrounding background — everything that is not "figure" is considered to be "ground" (Wong, 2010). In two-dimensional design, this can be exploited to create creative optical illusions; take for instance the well-known optical illusion illustration, shown in Figure 5, that can either be seen as two faces in profile or a decorative vase depending on what one considers to be figure and what one considers to be ground. 

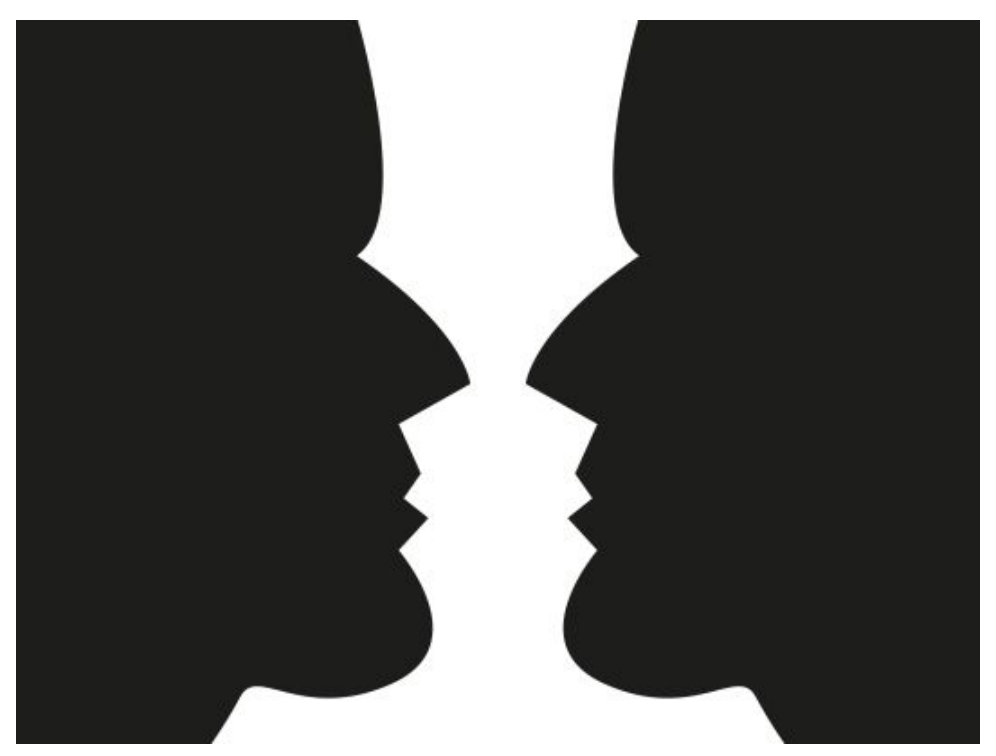

Figure 5. An example of the gestalt principle of figure \& ground; notice how you can simultaneously see a candlestick/vase in the center of the image, in white, as well as two faces in profile, in black.

"Figure/Ground." The Designer's Guide to Gestalt Theory, Creative Bloq, www.creativebloq.com/graphicdesign/gestalt-theory-10134960.

It is harder to create this sense of visual blurring in three dimensions, since the addition of depth makes it more obvious which elements are separate from the background. In fashion windows in particular, the background is often left relatively bare to showcase the items in front of it. In 2011, Louis Vuitton erected a set of circus-themed displays that lightly toyed with the relationship between figure and ground. Several windows in the series featured elephant statues that were patterned to match the backdrop behind them, giving the illusion that the elephants were blending into the backdrop, which can be seen in Figure 6. This played up the comedy inherent to the circus theme (in that elephants are ordinarily difficult to disguise). 


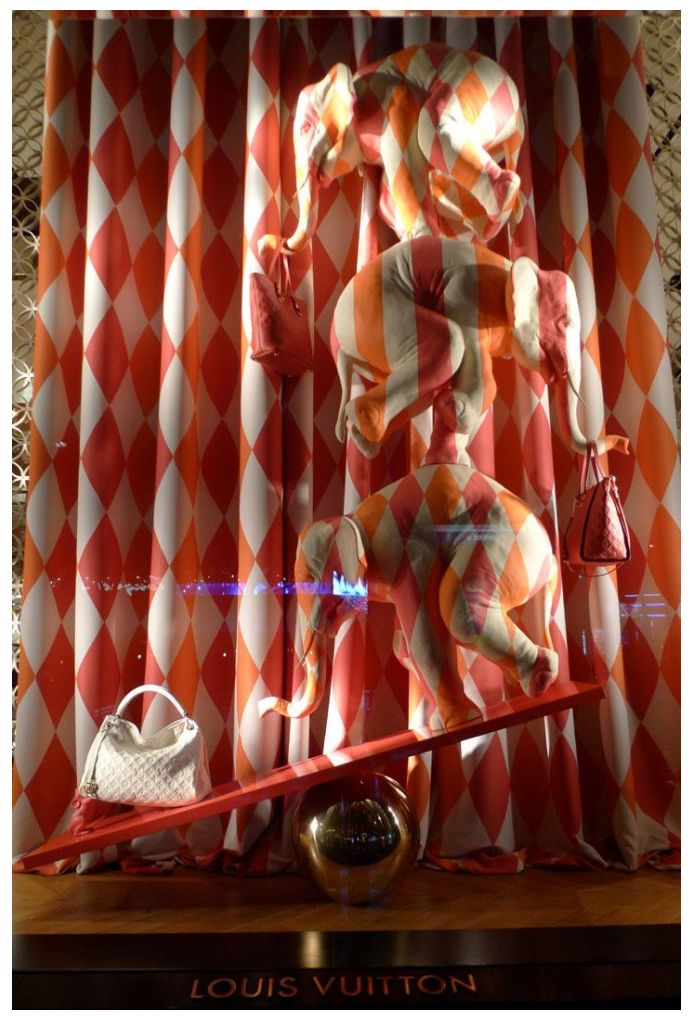

Figure 6. Louis Vuitton windows at a Paris, France store, 2012. "Circus Windows." Louis Vuitton Circus Windows, Paris, Retail Design Blog, retaildesignblog.net/2012/01/13/louis-vuitton-circus-windows-paris/.

The principle of symmetry is one that is frequently employed in fashion windows. Symmetry provides a sense of visual harmony, but as a result of this harmony, it can also fall into the trap of being visually uninteresting. As a result, symmetry is often used in fashion windows as a way to highlight an individual component that breaks the symmetry (in a fashion similar to the way the principle of similarity can be exploited). Examples include the Harrods Gucci Garden window (Figure 2), which used the symmetrical composition and identical nature of the bags to showcase the decorative elements customers could add at the shop's DIY counter. Tiffany \& Co's 2018 holiday windows in New York featured two panels of gingerbread cookie cutter shapes that were made asymmetrical by the random distribution of three crystal figurines, shown in Figure 7. 


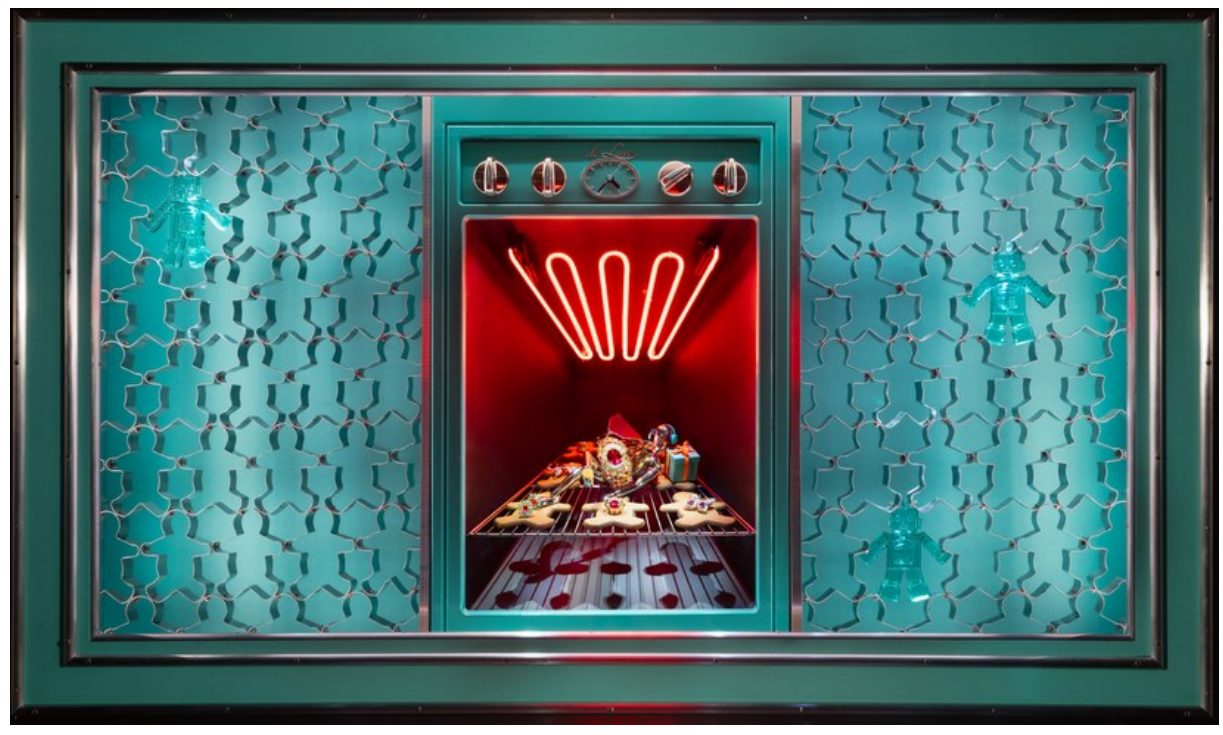

Figure 7. Christmas window display at Tiffany \& Co in New York City, 2018. "NEW YORK: Tiffany \& Co." International Christmas Windows 2018, VM Plus, www.vmplus.com.au/international-christmaswindows-2018/.

With these principles in mind, I would like to suggest a potential definition of the fashion window as a separate entity from other types of window displays. Fashion windows do not prioritize the display of garments or accessories, although they should contain at least one piece of merchandise in order to maintain their classification as a window display rather than an art exhibition. Furthermore, fashion windows include the merchandise as part of a larger design scheme that employs artistic methods to communicate information about brand identity.

\section{Visual Theoretical Frameworks}

I considered Roland Barthes' theories of semiotics as another potential theoretical framework, since one of the stated goals for this project is to 'read' visual content (1972). Semiotics is a commonly-used lens within the field of art history, and if one considers a 
window display as if it were an art tableau, it would suggest that semiotics could be easily employed. However, upon further consideration, I realized that the concepts of "sign" and "signified" work more effectively with individual objects, as opposed to a collection of objects. It is possible to mentally flatten a window display into paintingstyle tableau, but in doing so I feel that some of the important qualities that come out of a window's three-dimensional space are lost. Ian Verstegen also identified the importance of this three-dimensional space in Arnheim, Gestalt, and Art: a Psychological Theory, where he wrote that a gestalt-based psychology of art is equally beneficial for both simple images under reduced conditions of stimulation and rich images with ocularmotor cues, which are required in a three-dimensional visual plane (2005). Verstegen also wrote in collaboration with Roger Rothman about some of the weaknesses of semiotics as a theoretical lens for art history, and together they, too, suggested gestalt theory as an alternative (2007). I believe that the aspects of gestalt theory that they felt would be useful for the analysis of fine art will be equally useful in the case of display windows.

I decided to move away from semiotics due to what I perceived to be its weaknesses in multi-object installments or applications, and instead began to examine the existing literature regarding applied gestalt theory. I first encountered new applications of gestalt theory in an article about computer window design by Youn-Kyung Lim that suggested the existence of a phenomenon termed "interaction gestalt". The stated goal of the article was to develop an understanding of interaction as its own distinctive entity, "something emerging between a user and an interactive artifact" (2007, p. 242). The interactions take on a gestalt, a composition of the qualities of the individual, the interactive artifact, and the interaction itself. The resulting interaction gestalt is 
"experienced by a user and evokes the user's subjective experience of the quality of the interaction" (2007, p. 240). While I have chosen not to complicate my research by including digital window design as a subject for the MRP, this article inspired me to investigate gestalt further, as I felt it could lend itself quite readily to physical windows as well. The levels of interaction between the viewer of a computer screen and the viewer of a physical window are not so uncommon. In both instances, a pane of glass, bounded on all sides by a frame, separates the individual from the visual content they seek to consume. The interaction between a viewer and a window is not as direct as a user clicking options (for example) on a computer screen, but the act of viewing a display window is an interaction nonetheless.

\section{The Retail Environment}

My intention in conducting a conceptual and qualitative study of window displays is to contribute to what I discovered is currently a very small body of research in this vein. In terms of other conceptual studies upon which I can build, I have been informed by Opris and Bratucu's overview of visual merchandising and window display (2013) and Elizabeth's Vallance's comparison of window displays and still-life artwork (2009). Vallance conceptually re-framed the window display, choosing to discard contextual information such as clothing brands and prices and instead evaluated them on their merits as a type of still-life_-"with displays seen through the flat plane of the window, 'read' as paintings" $(2009$, p. 38). Opris and Bratucu's piece is quite short, and as such provides plenty of opportunity and jumping-off points for further research. They make the argument that window displays have evolved from their functional origins into hybrid of practical and art objects, a characteristic that I have also noticed. Furthermore, they call 
attention to the fact that window displays have been neglected within the literature even as recently as within the past decade.

In reviewing the current body of literature on window designs, I discovered that most of the authors came from marketing backgrounds (Sen, et al., 2002; Oh \& Petrie, 2012; Lange et al, 2016). These researchers approach the subject from the position of the retailer, attempting to ascertain what aspects - if any — of the window displays were enticing consumers to enter the stores. What these reports generally contain is a good deal of quantitative data, gathered with the intent of determining the efficacy of any given display. They also tend to use the language of 'visual merchandising', making it clear that the purpose is to successfully use visuals to push product. While the stated goals of this type of research differ from my own, this body of work provides a helpful foundation in regards to understanding the myriad different functions of a window display; they can function as advertisements and sales promotions (Klokis, 1986) provide information about the store's image (Sen et al., 2002), or serve as an informational tool regarding fashion and clothing trends (Beatty \& Smith, 1987). I plan to move away from this performance-evaluation approach to window display research, and instead move into a consideration of the windows" meaning rather than their "worth".

The research that I am building upon most closely is that which regards the affective quality of retail environments. This concept was first set forth by Pierre Martineau when he proposed the idea of "retail personality" in an aptly-titled article, "The Personality of the Retail Store" (1958). Within, Martineau explains that a store's functional and psychological characteristics create an aura of sorts that transforms a store visit from a simple errand into an "exotic adventure" or "fantasy world". His description 
of a J.L. Hudson's location in Detroit includes an explanation of the specific elements that develop the aura of luxury at the high-end retailer:

"The entire decor of the first floor presents a subdued effect of dark woods, cherry showcases in center islands, but with greater use of colour on wall panels and in various metal displays running from floor to ceiling. Hardware finish is bronze, of the richest type of finish available. [...] The type of fixture is significant. A quality store such as this uses a large number of showcases and center islands which lend a rich feeling to the store." (Martineau, 1958, p. 105).

Martineau's article has gone on to become something of a classic, as it formed a foundation upon which other researchers began to investigate the less-tangible aspects of the shopping experience. The research on window displays that followed Martineau incorporates his ideas almost as a given. For instance, Sen et al. (2002) make the argument that the consumer's evaluation of various merchandise in a store window as a way to provide information about the product categories available is conceptually separate from their usage of the same information to learn about the store itself. Martineau's blending of psychology with more traditional psychological research was an interesting break from the (only recently-established at the time of his writing) norms of consumer research. In the decades to follow, as marketers realized that the key to truly effective advertising lay within understanding the way consumers thought, this became a genre of research in and of itself. I regard the existence of this field of research - that of consumer psychology — as proof that gestalt theory can and will find successful application here. Martineau's “aura of psychological attributes” (1958, p. 98) hints strongly at gestalt without defining it explicitly.

Outside the realm of retail, the philosopher Gernot Böhme has suggested the concept of atmosphere in regards to architecture and space (2018). There is a growing 
interest and awareness in the role that atmosphere plays in architecture, both amongst currently working architects and to those who study architectural theory, largely due to Böhme's work. Brigitte Biehl-Missal built upon Böhme’s philosophical concept and applied it to a specific environment (the Frankfurt Stock Exchange) to emphasize how wide the potential applications could be. The foundation of the concept is that when approaching a visual encounter as an aesthetic situation, atmosphere explains how the impact of images derives from their aesthetic, emotional, and corporeal effects, as well as the mood and the cognitive responses they create (2013). Consumer psychology and marketing researchers Charles Dennis and Tamira King have made the connection between atmosphere and the visual and spatial components of shopping environments, which have been shown to have an impact on buying behavior (2007). Research on atmosphere generally applies to a building's interior space. However, window displays are an important tool in 'setting the tone' for a retail space, and as such have important implications for the overall feel of the store. In conjunction with gestalt theory, this research provides useful tools with which to analyze the composition of display windows, their relationship with the spaces in which they are situated, and the resulting effects this can have on those who view them.

\section{Saks Fifth Avenue and Luxury Shopping}

In addition to researching the environmental characteristics of display windows more generally, I felt it was important to cultivate a deeper understanding of the specific environment around the Saks Fifth Avenue display windows before I began conducting my fieldwork outside of them. First, a brief history of the business: Saks Fifth Avenue began as a partnership between two independent business owners, Horace Saks and 
Bernard Gimbel. In partnering, their goal was to construct a unique speciality store that would "become synonymous with fashionable, gracious living" (Saks.com). The location, on upper Fifth Avenue, and the fortuitous timing of the opening (1924, still the early years of the Roaring Twenties), added up to substantial financial success. The onset of the Great Depression dampened this early windfall, but Saks Fifth Avenue persisted and has since become a staple in the luxury retail scene. The brand's introduction to Canada followed their acquisition by The Hudson's Bay Company in 2013, with the first store opening in Toronto, Ontario in February of 2016. The Toronto store, located within the same building as a Hudson's Bay store on Yonge St, was the first flagship store Saks had opened in forty years (Kopun, 2016).

Competition for the eyes of luxury shoppers has increased significantly since the 1920s. At its inception, Saks' competition included the likes of Bergdorf Goodman, Neiman Marcus, and Barney's; today, there are not only more luxury department stores, but there are also numerous online counterparts. Net-a-Porter.com, ShopBop, Moda Operandi, and Canadian sites such as Farfetch are also part of the pool of retailers vying for luxury shoppers' dollars. The luxury shopping market has been growing consistently within the last few decades, becoming one of the fastest-growing industries in the world (Fionda \& Moore, 2009). There are multiple economic reasons for the growth, including the rising wealthy class in countries like China and Russia, increased buying power amongst working women, and the expansion of the middle class in North America who "are no longer at a financial distance from luxury" (Atwal \& Williams, 2009, p. 339). Cultural factors also play a part, such as media and pop culture's increased interested in luxury goods (Fionda \& Moore, 2009). Display windows sometimes draw upon this 
increasing overlap between pop culture and luxury to connect with consumers; take, for example, Saks' Holiday 2017 windows, which were all themed around Disney's Snow White.

One way that well-pedigreed department stores can maintain, and grow, their customer base is by reinforcing the characteristics that have carried them through decades of business in a commercial landscape that is constantly changing shape. These are the things that serve their symbolic function, which is one of the most important characteristics of a luxury brand (Fionda \& Moore, 2009). The sociologist Thorstein Veblen (1899) coined the term "conspicuous consumption", referring to an item's purpose in satisfying the consumer's need for status or self-esteem rather than physical or functional needs, and it remains highly relevant to any discussion of luxury brands. Saks, and stores like it, aim to be perceived classic, luxurious, and as having the kind of gravitas that can only be earned by nearly a century of history. This is all ideally communicated in the look and feel of the brick and mortar stores - which invariably includes their window displays. They are a key part of the experience of luxury shopping, which is what sets it apart from an errand run or a casual day at the mall. In an interview with The New York Times, Darcy Penick, the current president of Bergdorf Goodman, explained why they have continued to invest money into their window displays rather than scaling back to account for the fluctuating retail market: "[...] I think there is a natural orientation to pull back on things. From my perspective, that's not what drives customer love for your brand. You keep investing in the things your customers love." (Schneier, 2018). Even if the return on investment is not immediately or countably quantifiable, retail executives and customers alike still see value in window displays. In 
observing Saks today, one can see a marriage between different perceptions of luxury shopping. The spaces often evoke the feeling of a classic department store, while the wares reflect modernity.

\section{Holiday Window Displays}

Window displays are an important tool for luxury department stores year-round, but the displays erected in the month (or often, months) leading up to Christmas serve a slightly different function. November and December are the busiest shopping months of the year, containing two major holidays - American Thanksgiving, which goes hand-inhand with the major shopping holiday Black Friday, and Christmas. One may think that these occasions would ensure enough guaranteed revenue that retailers would not necessarily have to work as hard to capture customers, but in practice the opposite is true. Holidays window displays are often the most elaborate. Some stores start planning next year's Christmas window as soon as the current years' come down (Schneier, 2018). Macy's claims to have started the tradition of Christmas windows, especially in New York City, where the holiday windows along Fifth Avenue have become a well-known annual tourist destination. R.H. Macy unveiled the first Christmas window display at his 14th Street store in 1874. One of the first documented displays, dating to around 1910, contained a collection of porcelain dolls and scenes from the Harriet Beecher Stowe story "Uncle Tom's Cabin". In the years that have followed, the stakes for Christmas windows have been raised significantly: for example, Macy's is now known for the animatronic elements that are often included in their displays. Saks Fifth Avenue began their annual tradition of holding an event for the unveiling of their windows in 1914, possibly inspired by the early tactics of Arthur Fraser at Marshall Field's. This, perhaps more than anything 
else, underscores the point that Christmas windows are in many ways decorative displays first and merchandising displays second.

\section{Methods of Engagement with Window Displays}

Investigating the experience of the consumer is an integral part of my analysis, and as such, I have incorporated other experience-based theories. Phenomenology provides the term "experienced objects", which I consider highly relevant in explaining the way that window displays communicate meaning to their viewers. In "The Nature of the Object as Experienced," Edward Ballard (1976) wrote of his experiences with the Saarinean Arch in St. Louis: "When I try, though, to limit my awareness and my description to the mere fact of its being visibly there, to just that which is given, I immediately encounter difficulties, for I find at every turn that I seem to intrude my own interpretations" (p. 106). Ballard's experience is what I believe also happens with even the most passing, casual viewers of a window display, despite the fact that he was writing about his experience with a very large, standalone object. Rather than limiting our awareness to what is on display, we as viewers immediately and often unconsciously project our own interpretations onto the window.

The idea of objectified experience has been brought forward in the field of philosophy, most notably by George Santayana, and serves as a helpful companion to experienced objects. In his writings, he points towards the individual's tendency to sum up the whole of their life into a few accomplishments (when they are at the end of said life) and point towards them to say "this is who I am" (2012). Santayana's writings can tend towards the abstract, but I feel that his concept of distilling experiences and synthesizing them with others to create a clear concept that one can then use to define 
themselves by can be applicable to something as simple as a shopper's experience of a window display. It is my thinking that a successful window display artificially reproduces these experiences, in a way, to communicate kinship with the viewer and encourage them to come in and shop. To further explain what is meant by experienced objects and objectified experience, I can offer an example from my own shopping experiences. When I am shopping for leisure (as in, I have not set out with a specific purchase in mind), I am often drawn to windows that fulfill some sort of aspirational fantasy for me (Vallance, 2009). What makes these windows aspirational is both the products themselves and the style in which they are arranged. Experienced objects in these windows might include garments that I have seen previously on an influencer that I admire (or garments similar to ones they have worn), which now have a specific connotation and set of experiences that are unique to me associated with them. The shop may be attempting to curate a collection of clothes that are inspired by that influencer's style — and others like them, as style influencers often borrow style cues from each other-in order to appeal to a market of people who would like to embody this style that they assume exists. In this way, they are attempting to objectify the experiences that people have associated with this particular aesthetic. These definitions will become clearer as I choose specific windows and deal with their contents directly.

Pine and Gilmore (1998) have suggested that we should consider experience across two bi-polar constructs: customer participation and customer connection. Atwal and Williams adapted this framework to apply it to a study of experiential marketing in the luxury sector, and proposed four "experiential zones", shown in Figure 8: entertainment, education, escapist, and aesthetic (2009). 


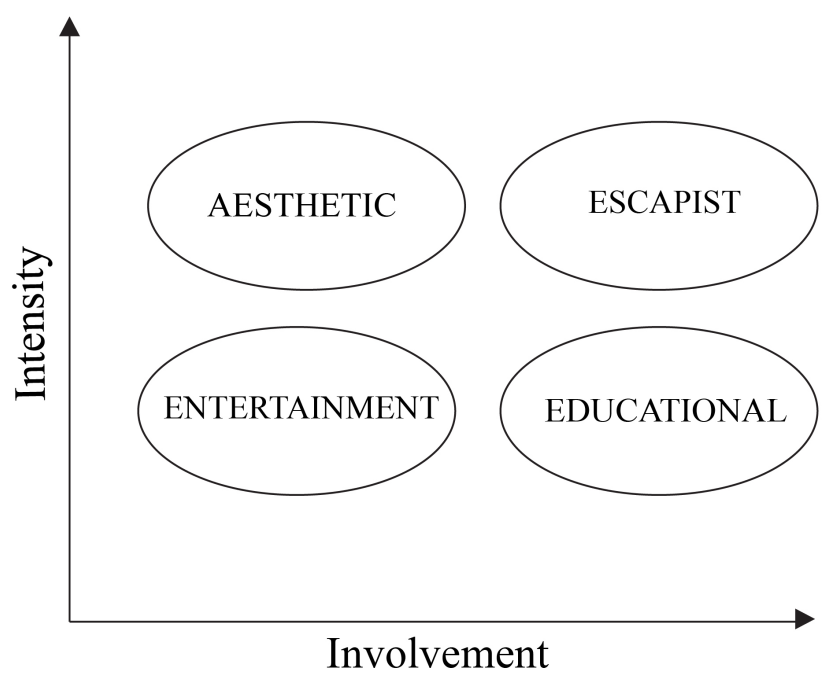

Figure 8. Park \& Jaworski's Zones of Engagement. Atwal, G., \& Williams, A. (2009). "Luxury Brand Marketing — The Experience is Everything!” Journal of Brand Management, 16, 338-346

Window displays occupy the aesthetic and entertainment zones. The entertainment zone involves a low degree of both consumer involvement and intensiveness; examples of other experiences in this zone would include a fashion show at a designer boutique, or a restaurant within a store (Atwal \& Williams, 2009). In this zone, the experiences are simply taken in. An aesthetic activity, in comparison, has a higher degree of intensiveness but a similarly low degree of involvement. Here, consumers immerse themselves in an experience but have little active participation. The difference between these two zones in terms of window display comes down to the level of enthusiasm on the part of the spectator; those who stop and spend time examining the window would be having an aesthetic experience, whereas those who simply walk past simply absorb them as a facet of the department store. Gestalt theory states that the consumer's true experience of shopping at Saks must be a function of how all of these zones are incorporated. The window displays occupy a part of two of these zones, but 
there will be still other experiences within these same zones and the others that coalesce into the full experience.

In conclusion, my review of the research regarding window displays revealed that there has not been much in the way of focused conceptual studies on this topic. As a result, I have drawn from multiple related fields in order to form the foundation for my own research. Gestalt theory provides a framework through which viewers, display windows, and the interaction between the two can be analyzed. This is supported by the phenomenological concepts of experienced objects and objectified experience, as well as existing research on architectural atmosphere and retail personality. The analysis is also supplemented by research on consumer psychology, which provides terms and tools through which I can more fully understand the experiences of the individuals I observed during my fieldwork.

\section{Non-Academic Sources of Information}

A larger existing body of writing about the intentions and motivations of window display comes from window dressers themselves. Martin Pegler is one such author, having worked as a designer (in conjunction with other roles) for over forty years. He has written more than sixty books on the subject of window displays. Many of them are compilations of what he considers to be the "best" windows from his point of view as a designer-someone who knows the process behind constructing a window, and who can therefore appreciate elements that casual viewers may not. I also consulted Simon Doonan's memoir, Confessions of a Window Dresser-Doonan, like Pegler, is a longtime designer who offers a look behind the scenes in his book, discussing the logistics behind working with Barney's, a large, upscale department store that has multiple windows and 
maintains many parallels with Saks Fifth Avenue. Despite confessing to having strong creative vision, Doonan categorizes window displays as advertisements, positioning himself as being somewhere in between artist and marketer. He writes: "though less targeted than a direct-mail campaign or magazine advertising, windows are capable of expressing whichever specific nuance of image your store wants to broadcast, be it hipness, affordability, quality workmanship, snobbery, nostalgia, pornography, or New Age earthiness" (1998, p. 9). While interesting, these texts are personal and autobiographical in nature, and as such lack the standards and rigor of academic research.

Researchers can speculate as to how theories such as gestalt may be relevant to the craft of window dressing, and to what degree designers take these design theories into account, be it knowingly or subconsciously. First-hand accounts such as Doonan and Pegler's offer an opportunity to see how this speculation holds up in the case of individual experienced window dressers, which make them valuable companions for an academic analysis. While neither author makes explicit mention of any deliberate implementation of specific design theories, there is still evidence of its presence; in a section encouraging would-be window dressers to 'copy other people's windows', Doonan (1998) writes: "Liquor stores and supermarket windows in particular demonstrate the power of obsessive repetition. Obsessive windows that look as if three people went blind putting them together are a compelling sight" (p. 196). This sentiment is echoed in the gestalt principle of similarity.

These personal texts, taken in accordance with the academic literature, contextualize the current presence of window displays in literature. The analytic portion of this research project takes the form of an autoethnographic account. By writing in this 
way, I have borrowed themes from these non-academic texts while remaining in line with the rigor expected of academic research. I will continue to justify this research design in the methodology section to follow. 


\section{CHAPTER THREE: METHODOLOGY}

\section{Introduction and Research Question}

In conducting this research I aimed to explore what the experience of viewing a display window entails and how this experience can be understood through social science theories. After suggesting a potential definition of the fashion window in theory, I have implemented an autoethnographic research design in order to explore how the public interacts with them in real life. This required an analysis of the the windows themselves, in terms of both content and intent, as well as an analysis of the viewers. I wanted to examine how these varied elements could come together, and what type of experience would ultimately result from this union. To explain the methodological choices that were made in order to carry out the research design for this project, I will elaborate upon the elements of ethnographic research that were employed in preparing for and carrying out the fieldwork that accompanied this project. An explanation of the coding processes that were employed for the purposes of organizing and finding meaning within the resulting field notes follows. The final section explains the ways in which the results of coding and the conventions of ethnographic writing influenced the organization and style of the analytical chapter of the MRP.

\section{Research Design}

I employed an ethnographic methodology in my research design for this project. The ethnographic research design employed in this project differs in a few significant ways from ethnographic tradition — an explanation of why, and in what ways, follows. As a research approach, ethnography is a useful tool for observing people in their cultural 
setting, as well as the ways that they interact with one another and the environments within that setting. Ethnography as a research method has its roots in social anthropology, but has since found applications in a wide array of different fields, giving rise to the term “adjectival ethnography" (Van Maanen, 1988). Examples of adjectival ethnographies include "urban ethnography", "medical ethnography" and "industrial ethnography", to name just a few (Van Maanen, 1988). While there are several accepted methods of conducting ethnographic research, participant-observation remains one of the most wellknown and commonly used. Early applications of this style have been criticized in more recent years for the level of detachment between the researcher and researched that emerged in the final monographs, but this style has since evolved to become much more collaborative between the researcher and the subject population (however, this is not true of this ethnography, which is deliberately one-sided). What ethnographic research succeeds at creating is rich, "thick" descriptions of a smaller area or grouping of people (as opposed to a less personal and more quantitative research method, which can pull larger quantities of less detailed information from a wider area or segment of a population) (Van Maanen, 1990). John Van Maanen characterizes this strength as one of the responsibilities of ethnography; he writes, "the trick of ethnography is to adequately display the culture (or, more commonly, parts of the culture) in a way that is meaningful to readers without great distortion" (1988, p.13).

I chose an ethnographic approach for this project because the goal of my was research was to gain a type of understanding of an average viewer's experience of the holiday window. However, my approach to ethnographic research differs from the established methods in a few aspects. The majority of ethnographic research combines 
notes taken by a participant-observational researcher coupled with interviews, generally with a few key figures selected from the subject population. My participation as the researcher was limited strictly to observation; I did not issue any surveys or conduct interviews with any of the people who came through the site of my observations. Ethnographic research is also most often conducted within a culture that the researcher considers "other" to their own in some way, although this is not always the case, particularly within more modern ethnographies. I have deviated from this tradition in choosing to observe a culture that I am already a member of. Furthermore, I have previously visited the fieldwork site on multiple occasions prior to choosing it as an area of interest for my research. This lends me a degree of familiarity with the site, a potential benefit that many other ethnographic researchers do not have.

An element that is common to almost all ethnographic methodologies is the keeping of fieldwork notes. There are as many methodologies of writing and keeping fieldwork notes as there are researchers. For example, those conducting a long-term ethnographic study may keep two types of notes: a small notebook kept on their person at all times and used for jotting down short thoughts and musings, paired with a much more detailed diary that the researcher adds to at the end of the day, making references to their shorter notes. This is just one potential method. It is true that for many ethnographic research studies, the writing of more detailed research notes happens at the end of the day, and this is the record that the researcher will primarily draw upon in writing their final analysis. In the case of my short-term study, the shorter observation notes and the more descriptive analytic passages were written simultaneously. 
Because of the specific nature of my ethnographic research design, it is more accurate to describe the methodology as being autoethnographic in nature, rather than ethnographic. Autoethnography is a newer term, developed to describe the cultural study of one's own people (Hayano, 1982). There is discussion and debate within the field of anthropology as to how an autoethnography should be properly conducted. Some, like Leon Anderson (2006), identify different styles of autoethnography: "evocative" autoethnography, which draws upon postmodern sensibilities to distance itself from the ethnographic tradition, and "analytic" autoethnography, a new term Anderson proposes to describe autoethnography that more closely resembles other types of ethnography in its efforts to offer what is essentially quantitative research. Autoethnography raises different questions in regards to ethics and representation, as the presence of a bias is often undeniable. My final analysis is composed almost entirely of my own thoughts on and interpretations of the actions of members of a culture to which I also belong, and I have made an effort to position myself and any aspects of my person that may influence my interpretations early in the analysis in order to be as transparent as possible.

Ethnographic research often employs a grounded theory approach, pioneered by Glaser and Strauss (1967), who describe it as the discovery of theory from data. A researcher using grounded theory constantly compares and contrasts their data against an established theory or one of their own formulation, ultimately concluding that the data either supports or does not support the theory. I chose not to employ grounded theory in my ethnographic research design, as it is not my intention to develop theory. It is true that I set out into the field with a few expectations of what I might observe, but these expectations were only informed by my prior experiences of the site as a civilian. I had 
no preconceived theoretical assumptions prior to the initiation of the fieldwork. My intention for this MRP was to explore how, or if, an ethnographic approach could apply to display windows, as the current body of research tends to characterize these spaces as commercial rather than cultural. As a result, because of my approach, the results of this research project are empirical in nature.

\section{Fieldwork: Reflections on the Field}

To collect the data that would subsequently form the basis of my autoethnographic analysis, I conducted fieldwork outside the Yonge Street-facing windows of Toronto's Saks Fifth Avenue location. This fieldwork was conducted in six shifts, each occurring on a different day. The shift length averaged at three hours, with a break of between fifteen and thirty minutes for rest and reflection. I tried to select a variety of days and times; for instance, weekdays and weekends, as well as morning, afternoons, and evenings, in order to observe the windows in as many unique situations as possible. While the weather was not under my control, I was lucky enough to be able to experience a range of different temperatures and weather conditions as well. I remained on the same street, observing the same set of windows, for the duration of the fieldwork, but my specific position shifted from day to day. I initially chose a spot as close to the center of the row of windows as I could, and remained in that location for two shifts. During these shifts I remained standing, and took my notes that way. This proved both difficult and uncomfortable due to my physical limitations and external factors such as high winds, and so I subsequently changed my methods for the remaining shifts. For the last four shifts I brought a small camping stool with me. The increased comfort that this provided allowed me to remain outside for longer and therefore spend 
more time gathering data. I also chose to position myself in front of a different window each day, to see if any of them were receiving more or less attention than any of the others.

In my fieldwork diary I recorded every instance of interaction that I observed. The criteria I set for what constituted an interaction changed over the course of the research, however. The first two entries in the diary include any passing glance towards the window. My reasoning was that it would be best to start broad and try to record everything first, and then re-examine my notes from those early shifts to see what types of interactions provided the most information for future analysis and which proved largely inconsequential. Using what I learned from my first two shifts, I eventually narrowed my focus and chose to only record interactions that required more agency on the part of the observer. This included changing the direction or path of their travel, halting their travel entirely, or engaging in conversation with a companion about the windows. I recorded less data overall on these days, but the data I collected was more informative and allowed me to develop thicker descriptions for my analysis. While I did not have interview data to include, I did attempt to record as many overheard conversations as I could so that the direct opinions and observations of the subject population could be included to some extent in the final analysis without the need to interact with me directly. This allowed me to hear a truly unbiased account of their thoughts on the windows, rather than one that may have been tailored to suit me as an interviewer. 


\section{The Role of the Researcher}

This research project marks my first outing as a researcher in the field. I did not give much thought to how I was going to collect my notes, although in retrospect this is something that I should have given much more thought and preparation to. As mentioned previously, experienced ethnographic researchers will often keep different types of fieldwork notes. These include methodological notes, which deal with one's technique in collecting the data - for example, tricks that one discovers for improving the flow of interviews, or cultural tics an anthropologist picks up on that allow them to participate more freely within the subject population. There are also descriptive notes, which recount what has happened, and analytic notes, where the researcher begins to lay out their theories about how they presume that the culture they are studying is organized (Bernhard, 2002). I was only familiar with descriptive notes, and as such, those were the only type of notes I set out to take: an as-it-happens record of what I was observing. However, despite having no intentions to take methodological or analytical notes, in reviewing the fieldwork diary at the termination of the fieldwork period I found that I had done so anyways: during the periods of time where I would take a break and leave the fieldwork site, I would continue to take notes and reflect upon what I had seen in the previous hour or so. These notes include thoughts about my methodology — what equipment I should bring with me to subsequent shifts, how I should position myself to remain as inconspicuous as possible — as well as some early condensing of my observations into patterns and categories.

In both the ethnographic tradition of participant observation and the newer school of autoethnography, the experience of the researcher is an important element of the final 
research products. The lens that each researcher brings to their work and their observations is an inextricable part of the process and therefore should be addressed. To that end, I am documenting the challenges, successes, and emotions that I experienced while performing fieldwork for this MRP. The goal of my fieldwork was purely to gather observations. To that end, I wanted to make myself as unobtrusive as possible, in order to limit any effects my involvement may have on the data. This proved harder than I initially assumed it might be. This project marks my first attempt at fieldwork; before beginning, I was warned that at times it might feel incredibly awkward and silly, and unfortunately that turned out to be very true. Part of my socialization as a young woman is the inclination to take up as little space as possibly_parking myself on a busy sidewalk for hours at a time felt like the antithesis of this, and my first few days of fieldwork were marked by a good degree of concern about myself rather than focusing on my observations. I was concerned that I did not look stereotypically professional enough and would instead be branded as strange. Either would have resulted in what I needed, which was to be left alone to observe, but I was deeply concerned with the opinion that passersby held of me. Part of the reason why the first two days of my fieldwork were the most challenging was the lack of equipment I brought with me. I simply stood across the sidewalk from the windows, holding a pad of lined paper. There was nothing that could visually identify me as someone with an official purpose, and I was both emotionally and physically uncomfortable due to the cold and the challenges of standing in one spot for hours at a time. Yonge Street runs straight north from Lake Ontario, and as such, acts as a corridor for the wind — on more than one occasion a large gust of wind would throw my notes into total disarray, which was very embarrassing. After those first two shifts, I 
purchased a small camping stool and switched back to a notebook instead of a pad for my note-taking. Using the stool made it clear that I wasn't simply loitering, and the notebook was easier to control in inclement weather. I also wore a very large coat, which, with the hood up, almost totally concealed my face from all angles besides head-on. These small additions made the subsequent shifts much more comfortable, in both regards.

In addition to observing how passersby responded to the window displays, I also tried to observe how they responded to me. Despite my deep-seated concerns that everyone was both looking at me and judging me negatively, most people seemed determined not to see me at all and resolutely walked past without as much as a glance in my direction. There are a few possible reasons for this, in my estimation. Firstly, Yonge Street is a busy street for commuters and leisure walkers alike, so those who are commuting likely did not have the time to pay the windows, or me, any attention. Secondly, the high-traffic nature of the spot and various areas that provide shelter from the weather attract a good deal of transients. Those who have lived in Toronto long enough tend to develop an unfortunate habit of looking straight past these types of people, and I may have been considered to be one of them. The intersection between Queen Street and Yonge Street is also a popular spot for canvassers, another group that most locals passing through try hard to avoid and that I may have resembled to some degree. The final possibility, of course, is simply that no one cared who I was or what I was doing. In all of my hours of fieldwork, only one woman approached me to inquire about the purpose of my presence. She asked if I was performing a protest, and when I informed her that I was doing observational research, she did not care to discuss further and moved on. The only other direct interaction of note occurred on my very last day of 
fieldwork, when I brought a camera and tripod with me to capture photographs and video footage of the windows. For the most part, the addition of this equipment encouraged people's inclinations to leave me alone, whether for fear of interfering or of being asked to participate. One woman, however, approached me to tell me that I was not allowed to take video on that sidewalk — she was not affiliated with Saks or the Hudson's Bay Company in any way that I could tell, but was simply a citizen concerned about privacy. I had the sense that she wanted to argue with me, but after informing her that the footage was for research purposes only (and that I had looked into the ethics regarding filming in public spaces) she moved on. I will admit to being disconcerted by the interaction, however, and I wrapped up the shift not long after that.

After a few shifts where I noticed that the percentage of passersby who were interested in the window displays was lower than I initially predicted, I began to wonder if my presence was exerting a larger influence than I may have realized. I suspected that I may be making people uncomfortable in some way, particularly if they (correctly) guessed that my intention was to observe them, and so they would hurry past the windows in order to avoid my gaze. To try and alleviate this problem, I decided to start sketching the windows in between taking observational notes when I noticed significant interactions. It is hard for me to know if this solved the original problem, but it did result in some slightly different reactions from those walking by. Some still hurried past, I suspect out of politeness so as not to be obscuring my "subject", but others would observe me sketching and then turn to the window displays with renewed interest.

My fieldwork experience was characterized by a good degree of trial and error and self-discovery in the face of my inexperience. If I were to do it again, there are things 
that I would do differently, but there are also many things that I would choose to keep the same. I will explore this in further detail in a later chapter. Now that I have gone into some detail about where I fit into the environment I was observing, I can begin to discuss what it was that I observed.

\section{Data Analysis Process: Coding}

After transcribing the notes from my fieldwork, coding them was the next step in beginning to draw out meaning for analysis. There are many different approaches to coding qualitative research, but as a researcher embarking on the process for the first time, I chose to keep my methods fairly simple. As a novice coder, I chose to code all of the data that I collected rather than selecting specific excerpts for coding. There are differing opinions on this approach: some researchers feel that this method, which accounts for minute detail, can generate significant social insight (Lofland et al., 2006). Some are of the opinion that up to half of the total record can be summarized or deleted, leaving only the most salient portion for coding and analysis (Seidman, 2006). This latter technique requires a degree of skill and confidence in scanning data to quickly determine relevance that I do not feel I have developed at the time of writing. Furthermore, due to the relatively short duration of my study, I did not have a body of data expansive enough to necessitate culling prior to coding. I also opted to code manually, rather than employing a coding software. Coding software is useful in the case of research that includes interviews or surveys, or for researchers who have a very significant amount of data to code. As my data set is limited in size and composed entirely of my own thoughts and observations, manually coding seemed the most appropriate approach. I also chose to code on hard copies of the fieldwork notes, due to the fact that it allows for more control 
over the work and can provide a sense of 'ownership' for the first-time coder that a computer monitor may not (Saldana, 2015).

I translated the raw data of my fieldwork notes into themes by working through two cycles of coding, with three rounds in the first cycle and one in the second. During this process, I was informed by a series of questions suggested by Emerson, Fretz, and Shaw, which include:

- What are people doing? What are they trying to accomplish?

- How do they do this? What specific means and strategies do they use?

- How do members talk about, characterize, and understand what is going on?

- What assumptions are they making?

- What do I see going on here?

- Why did I include them? (1995)

I first engaged in a round of pre-coding, during which I read through the entire series of notes and highlighted passages that struck me as potential "codable moments" (Layder, 1998). In a way, this allowed me to reduce the data set somewhat and streamline the amount of information without having to actually cull any of it. The passages that struck me as being potentially valuable for further coding included anything regarding demographic information (gender or age), overheard conversations, and any interesting information from the sections of personal reflection that I thought might prove valuable as jumping-off points for more detailed analysis later on.

The second round of coding is characterized as "initial coding". In this round I created "first impression" codes. These consisted of the most salient information from any passage that jumped out at me upon reading. Codes from this round included phrases such as "men", "women”, “window", and "discussion"- - very general phrases that primarily served to distill the information into a format that could be more easily 
compared and contrasted. I kept these codes in mind when moving on to the third round of coding, which was another round of initial coding. At this stage, however, I aimed to be more specific and descriptive, particularly in regards to codes that involved people. I had already begun to gather a sense that this would be a significant section of my analysis, and so it would be valuable to begin to split these more general codes into smaller groupings that could be examined in more detail. This strategy has been referred to as lumping and splitting; lumping gets to the essence of categorizing a phenomenon, while splitting encourages careful scrutiny of social action represented in the data (Saldana, 2015). The codes that emerged after this third round were more specific. "Women" and "men" became "mother-daughter pair" or "young men", for example. At the end of this round, I had thirty-five first impression codes.

During the first cycle of coding, I worked with the primary text of the fieldwork notes to draw first impression codes from it. For the second round of coding, I turned towards the resulting codes and began pattern coding to further refine them. Pattern codes are explanatory or inferential codes, ones that identify an emergent theme, configuration, or explanation (Miles \& Huberman, 1994). I chose pattern coding over other common styles of second-cycle coding due to the fact that pattern coding is one of the few that is well-suited to studies that do not employ a grounded theory approach. Furthermore, pattern coding is an efficient tool for the development of major themes from the data. In this study, the thirty-five first impression codes were organized with relative ease into three groupings based on similarity: "People", "Methods of Engagement", and "Environment". These three meta-codes were the primary themes that emerged from the data, and became valuable tools in the organization of the analytical chapter. As with all 
aspects of coding, there are multiple ways to compile themes and multiple ways to employ them. Themes give shape to the data and the codes that come from it (Van Maanen, 1990). Performing a thematic analysis (as opposed to a content analysis, which begins with predefined categories) allows categories to emerge from the data (Ezzy, 2002).

\section{Approach to Writing the Analysis}

The analytical chapter of this MRP is organized according to the final meta-codes that emerged at the conclusion of the coding process. These three codes are as follows: "People", "Environment", and "Methods of Engagement". While proceeding through the process of coding, my notes revealed that these were three key sites of meaning for the window displays that I observed. Each of these primary headings is further subdivided into more specific sections, which are based on the more specific codes that emerged from the final round of the first cycle of coding.

The content of the analysis consists of first-person evaluations of the information contained within the field notes. The research design is ethnographic (more specifically, autoethnographic) in nature, although it does not adhere to all of the conventions of ethnographic writing. Lacking interviews or survey data, the only available material for analysis are the researcher's own thoughts and observations. The analysis chapter consists of expansion upon these observations and the resulting reflections. Coding the fieldwork notes revealed the existence of patterns in regards to the types of individuals who engaged with the window displays, as well as they methods of engagement that they employed. In the analysis chapter, the researcher continues to build upon these patterns and relationships and develops a deeper understanding of the potential relationships and 
theoretical links. Because of the personal nature of the collected data, the analysis is written in the first person. This is in keeping with the style of ethnographic writing, and also serves to reinforce the fact that the analysis is informed by theory, but is nonetheless speculation on the part of the researcher and should not be considered to be fact. To emphasize this, the first section of the chapter positions the researcher both at the fieldwork site and within the research, as the researcher's perspective is an inextricable part of the observations and the analysis.

The analysis of the people observed viewing the window displays follows the section positioning the researcher. There were multiple codes pertaining to the human element of the research at the end of the first coding cycle, many of which dealt with specific demographic information such as age and gender. The analytical chapter goes into detail about what assumptions I brought to the fieldwork in regard to how age and gender would affect the way that people reacted to the windows, and how those assumptions played out in reality. An analysis of the window displays themselves, their surrounding environment, and the contextual information contained therein follows. In this section, the displays are analyzed and critiqued according to the principles of gestalt. They were evaluated on their merits as an individual display and with regards to how they served the stated theme of the series. The chapter culminates with an analysis of the different methods of engagement that were witnessed. It was necessary for this section to follow the analysis of the people and the environment they were situated within, as it is important to have an understanding of both of these elements before delving into the ways in which a relationship between them is created. 
With this research project, I have attempted to develop a research design that can demonstrate how social science theories and methodology can be effective tools for analysis in spaces that may not be generally recognized as cultural sites. Due to my relative inexperience as a researcher and the limited scope of this project, some deviations from ethnographic tradition were necessary in planning and carrying out both the fieldwork and analysis. 


\section{CHAPTER FOUR: FINDINGS AND ANALYSIS}

Introduction to the Analysis

This portion of the research project is written in the style of an ethnographic observation. I felt that this more personal style of writing lent itself well to this research subject, since my position and experience as the researcher is very relevant to the study of something as individual as the sensation of viewing. Furthermore, an ethnographic approach sets this project apart from the current body of literature, which is largely marketing-focused and quantitative in nature. The data I will be analyzing in this chapter comes from the notes that I took during six days of fieldwork, during which I was posted outside of the holiday display windows at Saks Fifth Avenue, observing everyone who walked past them. My purpose was to first examine the windows and the surrounding environment myself, to come to my own conclusions, and then to identify who engaged with the displays, as well as the nature of their engagement. I have broken my analysis into three sections: a discussion of the types of people, and groups, who observed the windows and what I suspect may have motivated their viewing; an exploration of the environment surrounding the windows, and the resulting ramifications this has on the viewing experience; and finally, an analysis of the different methods of engagement I observed.

\section{Analysis of Saks Fifth Avenue Christmas Window Displays}

The site of my analysis was one city block, stretching along Yonge Street between Queen and King Street. This location is shown in Figure 9. Along this block were five 
windows, labelled Window 5 through 9, with Window 5 being the northmost window, and Window 9 being the furthest south.

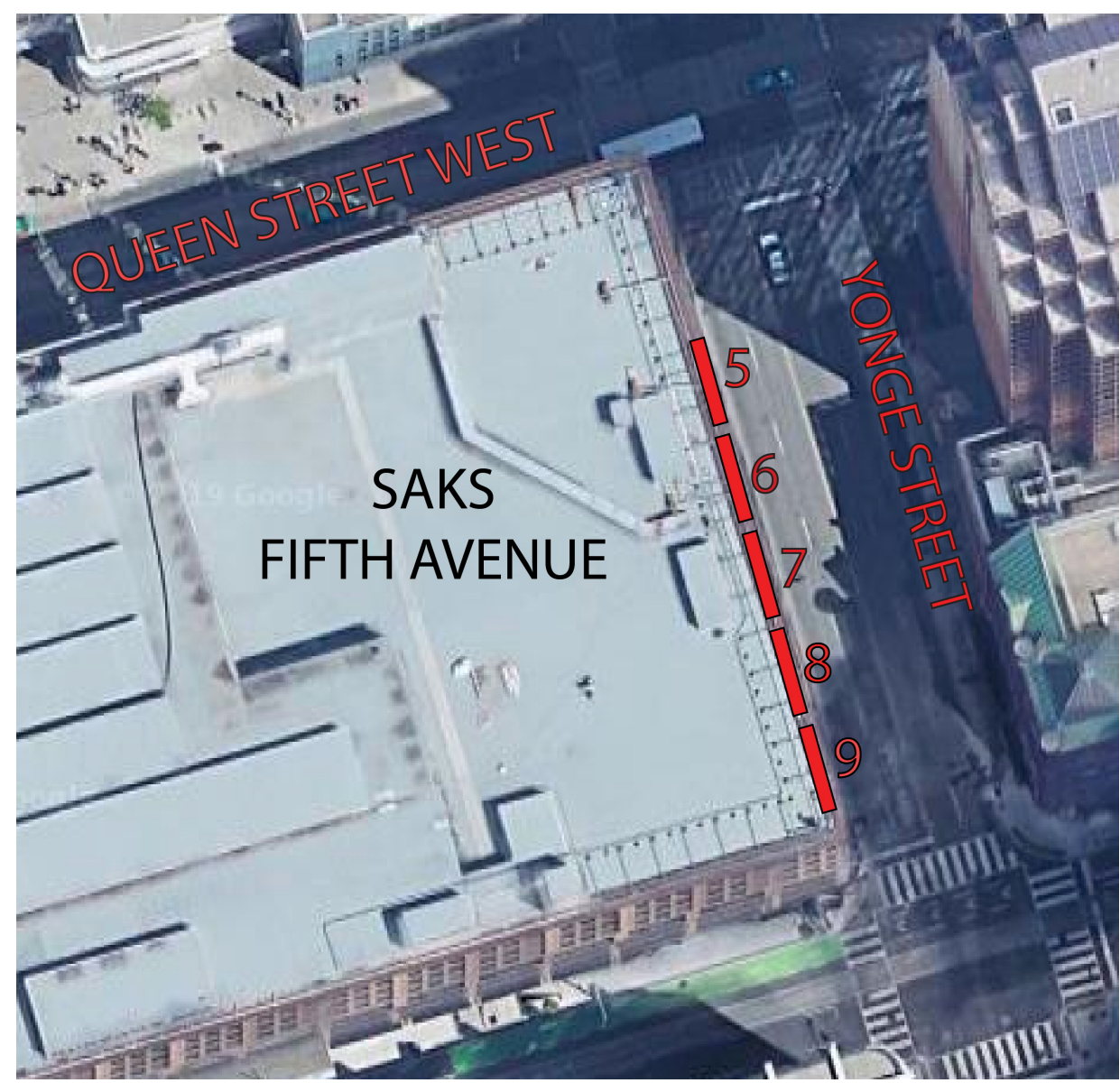

Figure 9. The location of Saks Fifth Avenue Toronto, as well as the fieldwork site. The location of the five windows examined are indicated here, labeled 5-9.

Before delving into an analysis of the public's reception of the windows, I first will examine the windows thematically, as well as in accordance with the principles of gestalt as they were laid out previously. This examination will cover the windows as standalone displays as well as components of a series. All the windows bore text reading 
"Theatre of Dreams", the title for the year's displays, and so they are unified under this common theme.

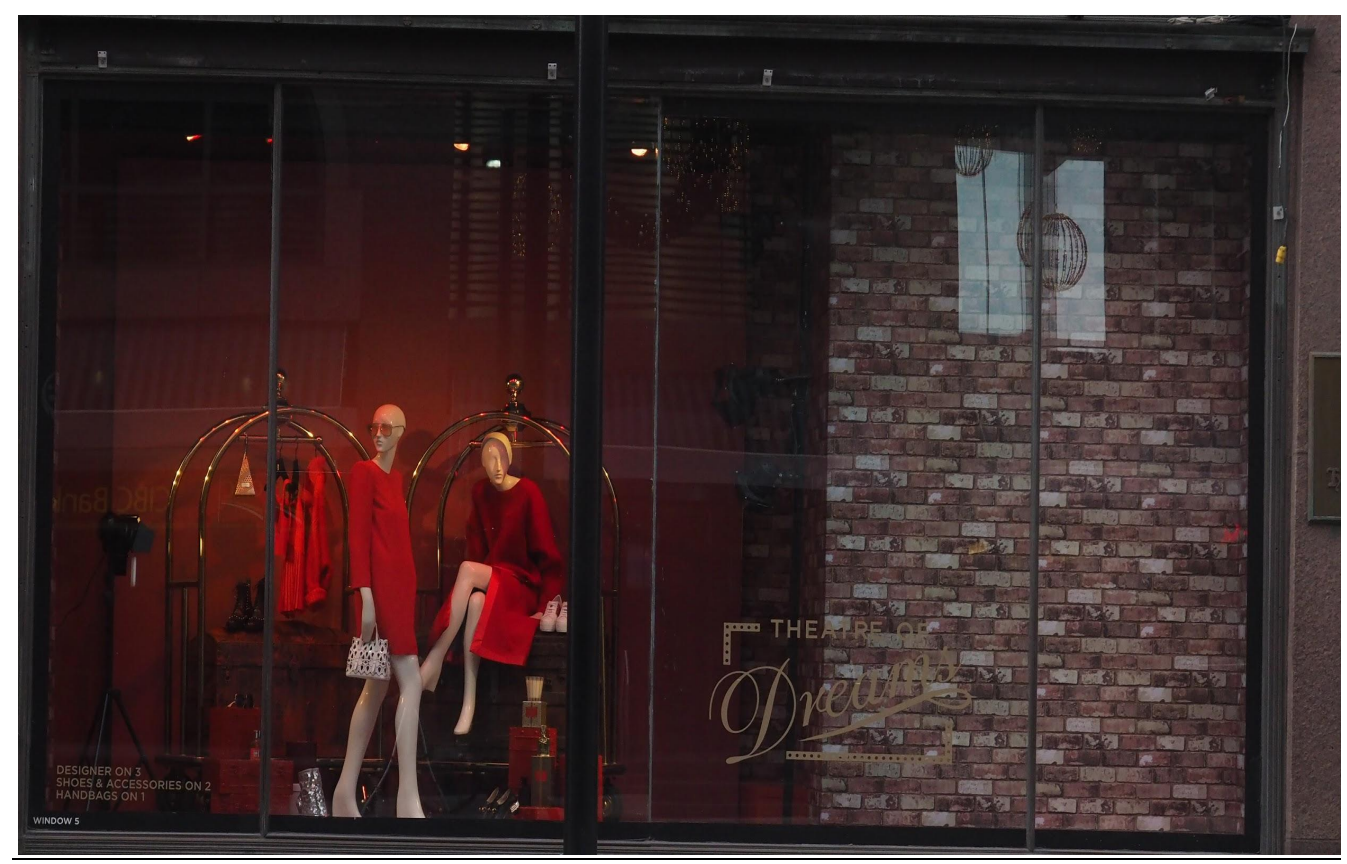

Figure 10. "Window 5" of Theatre of Dreams, Saks Fifth Avenue Toronto 2018.

Window 5, shown in Figure 10, is either the first or last window in the series that passersby encounter, depending on the direction of their approach. In either instance, it is somewhat lacking, especially when compared to the other displays. This display does have the disadvantage of having less available space than the other windows, as roughly half of the display is taken up by a wall that has been covered in brick-effect wallpaper. The display may fewer fantastical elements than some of the other displays, but the elements that are present are employed well with regards to continuity and leading the eye; the heads of the mannequins and the top rails of the luggage carts are all at roughly 
the same height, encouraging a viewer to scan smoothly across the display. As a result of this, however, the merchandise placed at the bottom of the display goes unnoticed.

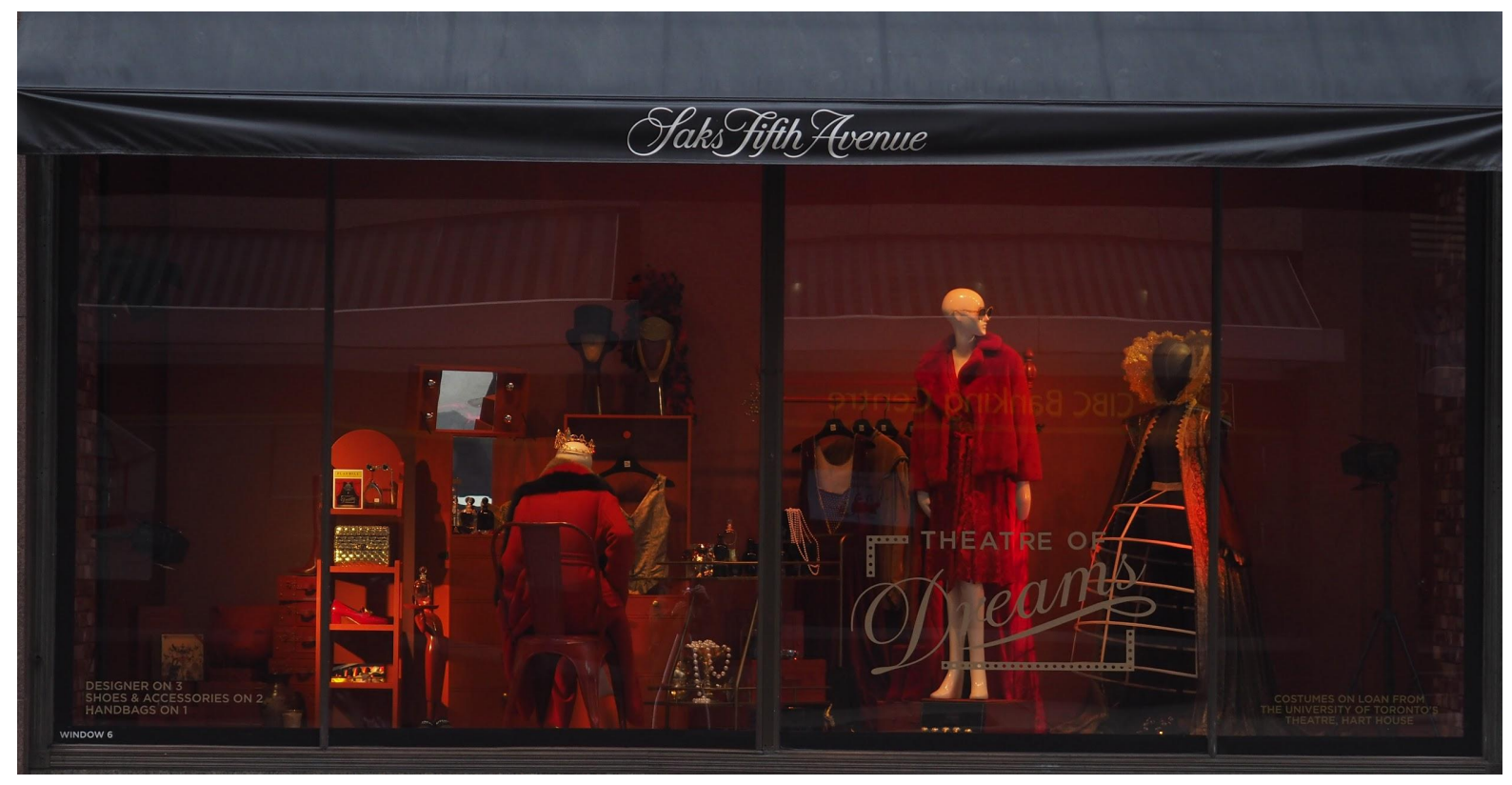

Figure 11. "Window 6" of Theatre of Dreams, Saks Fifth Avenue Toronto 2018.

Window 6, shown in Figure 11, stands apart from the other displays by including clothing that is not available for purchase. The mannequins are wearing merchandise, but all of the other garments in the window are costumes on loan from Hart House, the theatre at the University of Toronto. This is explained via text in the bottom-right corner, which is styled and arranged in exactly the same way as the shopping information that is in the bottom-left corner of all of the displays. This display is the only one that expresses the "theatre" element of Theatre of Dreams explicitly. 


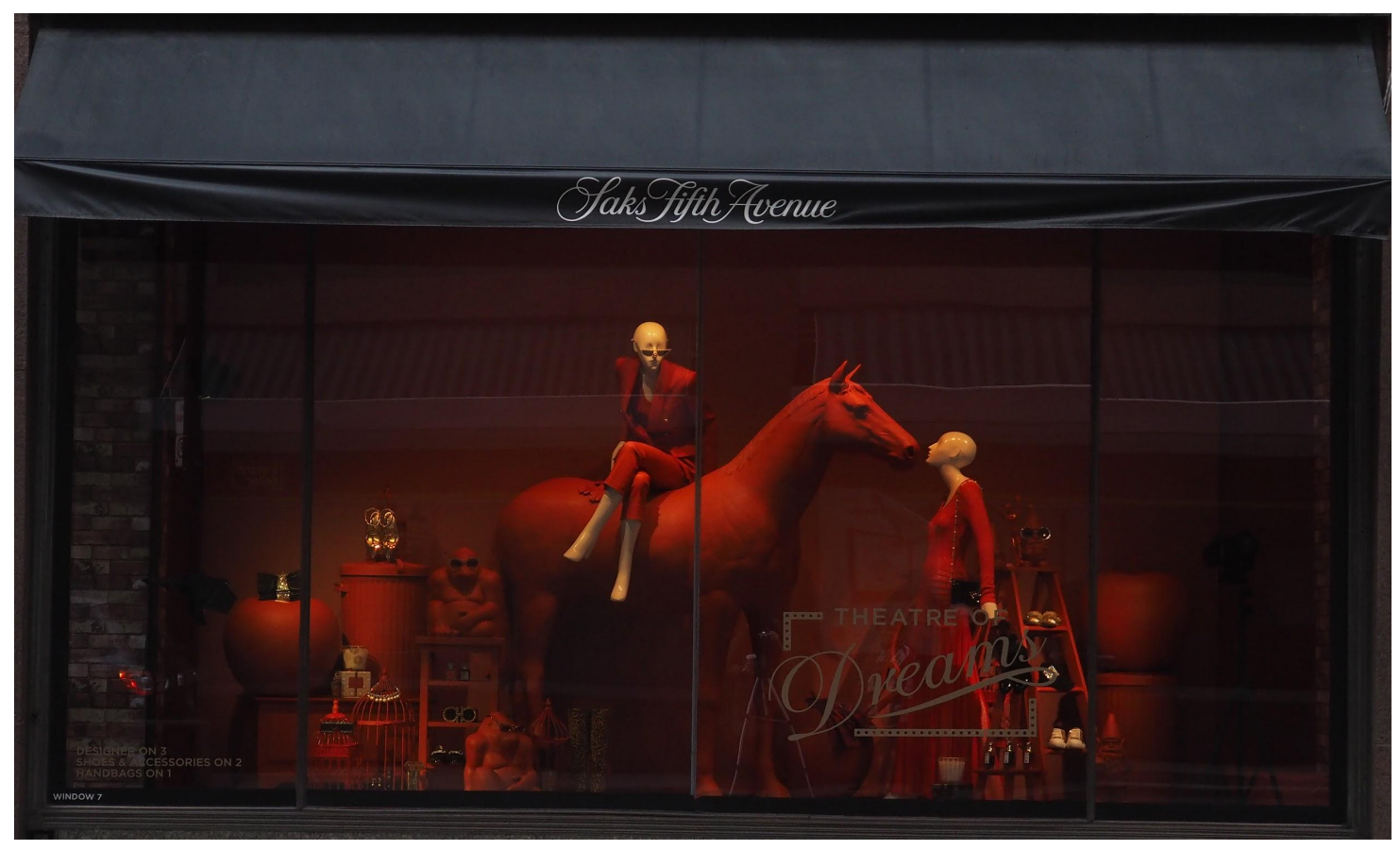

Figure 12. "Window 7" of Theatre of Dreams, Saks Fifth Avenue Toronto 2018.

Window 7 is in the middle of the series, and so it is the central piece when the windows are viewed together. Accordingly, it has the most immediate visual impact of the five, featuring a large, red, horse statue. There is no obvious relationship between any of the decorative elements in this display_-besides the horse there are also monkey statues, larger-than-life apples, and birdcages - which give the window an off-beat, dream-like quality. 


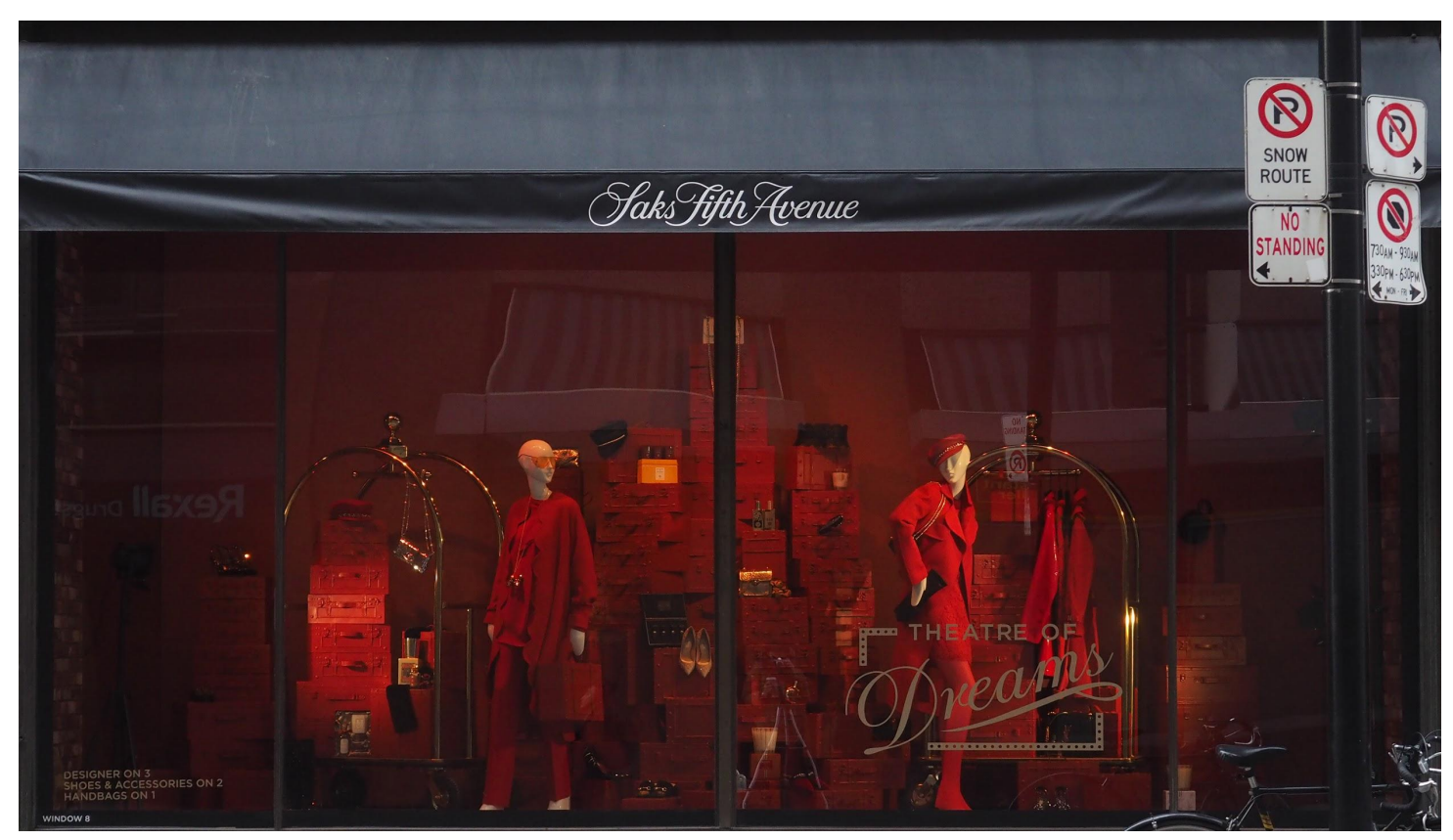

Figure 13. "Window 8" of Theatre of Dreams, Saks Fifth Avenue Toronto 2018.

Window 8, shown in Figure 13, employs the technique espoused by both Simon Doonan and the gestalt principle of similarity, which is that having an element in great numbers is a good way to generate visual interest. While it may not have the immediate whimsy of Window 7, Window 8 is one of the most interesting displays in the series design-wise. The columns of identical trunks draw the eye upward and showcase the merchandise stacked amongst them in an interesting way. Because the trunks are identical and stacked in such number so closely together, I interpreted them as larger shapes as well as individual items (in accordance with the principle of proximity) - in my case, I saw a city skyline in the staggered columns. 


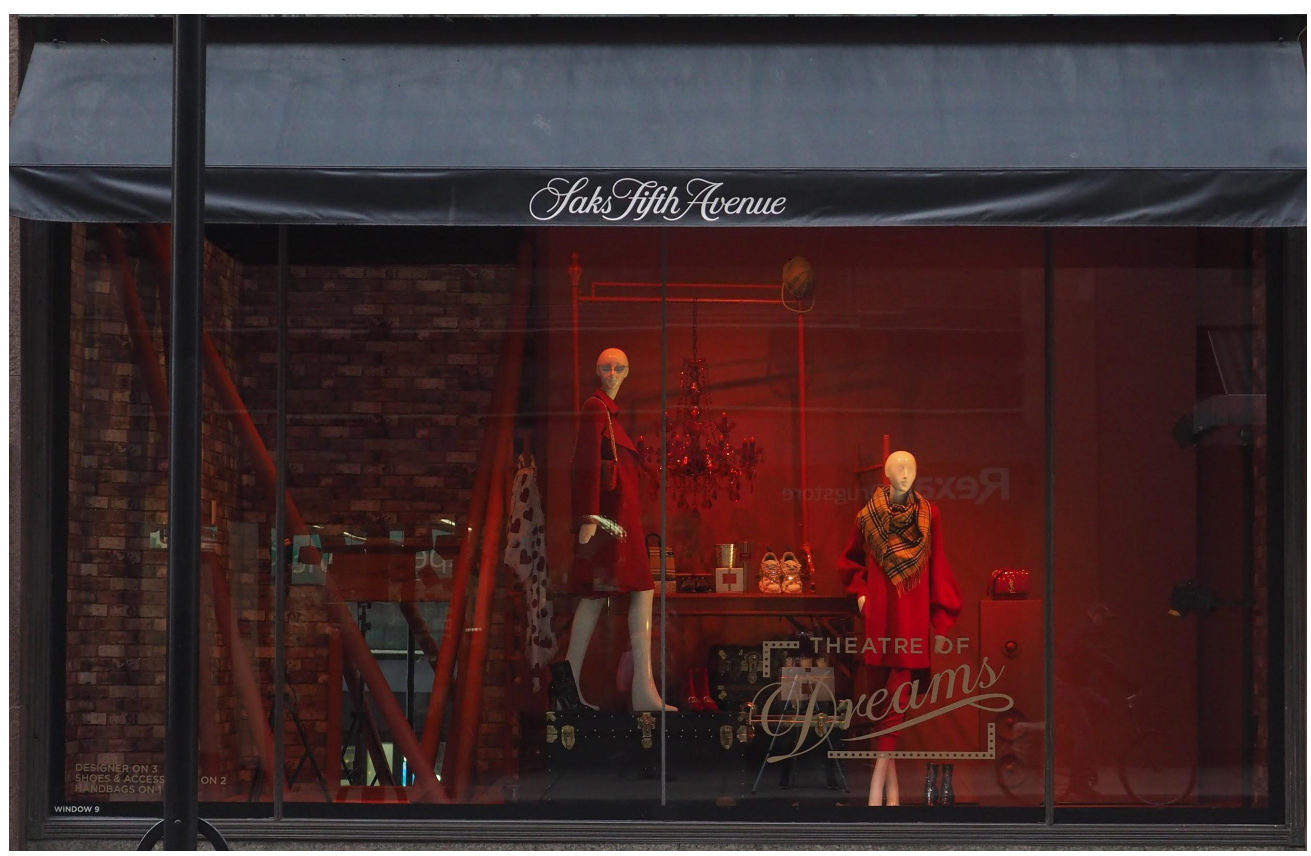

Figure 14. "Window 9" of Theatre of Dreams, Saks Fifth Avenue Toronto 2018.

Like Window 5, Window 9 (shown in Figure 14) is either the first or last window encountered. It is also similarly lacking. While Windows 6, 7, and 9 all have clear themes, Windows 5 and 9 showcase the merchandise in a much more straightforward way. When evaluating the displays from a design standpoint, this makes them the "weakest" of the group, but it also means that they may be more successful than the others as marketing tools.

When considered as a group, different strengths of the displays' designs can be seen. The most prevalent characteristic is the choice of colour. All of the windows feature a predominantly red colour scheme, in the floor and wall treatments as well as on the decorative fixtures and the clothing on the mannequins. There are symbolic connotations for the colour red for these displays: red is one of the traditional colours of North American Christmas celebrations, but it is also the colour of the ribbon used for AIDS 
Awareness (worldaidsday.org). The Theatre of Dream windows were created in partnership with Broadway Cares/Equity Fights AIDS, an American nonprofit that raises funds for AIDS-related causes (broadwaycares.org). This collaboration is not advertised anywhere on the windows, but for those who are aware of it the choice of colour is a powerful symbol. Choosing to implement the same colour for the floors, walls, fixtures, and clothing also changes the relationship between figure and ground in the windows, as it did for the Louis Vuitton circus windows in Paris (Figure 6). Because the threedimensional elements are the same colour and shade of red as their backdrop, the separation between them becomes less distinct. This hazy, indistinct translates the "dream" portion of the Theatre of Dreams.

The principle of proximity has interesting applications in three dimensions as opposed to two-dimensional design. Proximity in three dimensions also applies to the viewer's distance from the window in addition to the distance of design elements from each other. Depending on the vantage point from which one observes the window, the display takes on a different shape and quality. A person walking on the same side of the street at the windows will have a very different experience of the display as opposed to someone who is walking on the other side of the street. Before examining the contrast between these experiences, it is first necessary to establish the physical space outside of the windows and their position within the larger context of the city.

\section{Analysis of the Environmental Context}

The display windows I was observing are located on Yonge Street, between Queen Street West and King Street West (Figure 9). For anyone not familiar with the geography of Toronto, this is a very busy location. Yonge St is one of the primary north- 
south arteries of the city, as well as being one of its oldest streets. Queen Street and King Street both host major streetcar routes along their lengths, and are known respectively as a major shopping center and the heart of the city's financial district. As a result, both locals and tourists alike are constantly moving through through the intersections where Yonge cuts through King and Queen Street. The purpose behind an individual's presence in front of the windows is very important in determining whether or not they would choose to engage with them. During my observations, I noticed that the proportion of passersby who gave the windows more than a passing glance, or even that much, was lower than I had expected to see going in. Gestalt theory guides me to look beyond the borders of the window and consider the full environment in my analysis, and I believe that there are several factors provided by the surroundings of the windows that may help to account for what I perceived as a lack of interest.

Firstly, as I have mentioned, the sidewalk that runs along the display windows is busy with commuters. People getting off of a streetcar to go to work, for example, view the stretch simply as a part of their routine. These individuals see every iteration of the Saks windows as they change throughout the year, and while the additional spectacle of the holiday windows may have caught their eye when they were first unveiled, the displays quickly faded into the background of their everyday lives again. I would venture to say that this type of person accounted for the majority of the passersby I observed, as my fieldwork was primarily conducted on weekdays. In contrast, the window displays for the Hudson's Bay Company around the corner to the north on Queen Street West attracted a much different crowd. Continuing west from these windows takes one to Nathan Phillips Square, and then into the shopping on Queen Street West. Despite the 
extremely close proximity, I would argue that the types of people travelling on these two cross streets had very different motivations. To simplify, Yonge Street is for commuters, while Queen Street is for shoppers (and tourists). This affects even those who are on these streets for other reasons; even if you are simply walking for leisure, if you find yourself on a busy sidewalk full of commuters, it is hard not to move in the same purposeful and somewhat rushed way that they do.

The physical space of the sidewalk is important to consider as well, as it has implications for the way that the principle of proximity translates to three-dimensional gestalt. On the window side of Yonge Street, the sidewalk is only slightly wider than a standard city sidewalk. In some areas the concrete is broken up by metal grating (due to the subway system operating underneath), and while it is possible to walk over the grating, many choose to walk around it instead, or they are forced to due to incompatible footwear. This narrows the sidewalk significantly in a few spots and concentrates the foot traffic accordingly. The volume of traffic that this stretch of road receives, coupled with the relatively small space, left little room for anyone who wanted to stop and look at the windows to do so. In order to get a detailed look at the displays, one would have to step to either side: right up against the glass, or back, near the street. This reduced the dimensions within which one could experience the window. The only options were to observe from either from three inches away, or three feet. Close-up, it is easier to see the smaller details in the window. Items such as a pair of sunglasses or earrings, or a candle, can become the focus. Viewing from this angle also illustrates the value of including merchandise that is clearly branded, as it makes it easier for a potential shopper to find the item they saw in the window in the store, if they so choose. The three-dimensionality 
of the window is also more apparent from this position. By standing farther back one experiences in its entirety, or nearly so - the view is usually partly obscured by people walking past. Those walking on the other side of the street are able to see not just one window in its entirety, but several. These viewers miss out on more of the details of the display, but are able to experience them in context as part of a series instead of one-at-atime.

To illustrate how important the space in front of the window is, let us again contrast the Saks windows to the Hudson's Bay windows on Queen Street. The sidewalk on this side of the building is nearly twice as wide as it is on the Saks side. This affords Hudson's Bay the space to place very large nutcracker statues in front of the windows, which in and of themselves have significant influence on the way in which one views the HBC window displays. The nutcrackers are visible from a great distance-you can see them from much further away that you can see any detail of the windows. From that distance, they immediately signal that there is something worth looking at; Hudson's Bay communicates very clearly that they held nothing back for their holiday windows, and that you will not be disappointed by choosing to approach and get a closer look. Another feature of the wider sidewalk is that it affords the space for congregations of viewers to form. This is further assisted by the fact that there is not nearly as much foot traffic on that side of the building, and so the instinct to get out of the way of purposeful walkers is lessened. Crowds beget crowds; once a gathering has formed, more people are likely to join in and see what has caught everyone's attention.

Another element to consider is the way that the windows are framed. Technically, every window display is bounded by six planes, as opposed to the single plane of a two- 
dimensional scene. However, viewers can only interact with one side: the glass. Viewed from a distance, the three-dimensional space of the window undergoes some visual compression that brings it closer to the experience of looking at a traditional twodimensional art piece. Because window displays are (usually) representatives for a business, there are often other framing pieces that provide context and additional visual information. In the case of the Saks Fifth Avenue windows, this includes a small, black, overhanging canopy printed with "Saks Fifth Avenue". Between the windows, set into the stone of the building, are metal plaques indicating the heritage of the Hudson's Bay Company (the building that Saks is located within). The relationship between Saks and $\mathrm{HBC}$ is an important element of the environment that the window displays exist within. The two are not explicitly affiliated, in that they do not specifically reference each other in any official marketing materials, but the two department stores are both under the Hudson's Bay Company umbrella. In Toronto, the two also occupy space within the same building, and even share an entryway and information desk. As a result, I believe that shoppers experience some blurring of the two, which is exacerbated by the branding on the side of the building. The Saks marquees and the HBC plaques exist side-by-side, and I observed two instances of viewers who were unsure which business the windows belonged to. In one case, one of two women exclaimed, "The Bay!" upon seeing the windows, only to be corrected by her companion. A similar exchange happened again within the hour.

While the window displays are the most direct way for Saks to make a statement about their retail personality, the rest of the exterior space also speaks to this. Firstly, the size of the windows (larger than the average non-department store) and the number of 
them that Saks has at their disposal shows that they are a company that is able to afford a large piece of real estate. This develops a sense of prestige from the first moment one encounters the store, even when just viewed from a distance. Other elements such as the customized canopies and plaques reinforce that Saks is an established brand that knows themselves well. For an uncertain shopper, this type of confidence can be reassuring; they are putting their spending money in the right hands. A repeat customer can feel similarly good about their choice to align themselves with a prestigious brand.

\section{Implications of Viewer Demographics}

In the following sections I will discuss the various types of people I encountered during my fieldwork. Interviews and direct interaction were not incorporated into this research project, and as such the conclusions I have drawn are based on contextual information and my own interpretations therein. As a researcher performing autoethnography, it is also important that I position myself as one of the players within this scene. While the ethics set out for this project prevented me from seeking out interaction with passersby, many reacted to my presence in both direct and indirect ways. If I had chosen to conduct this research in a way that included interviews or conversation with passersby, I would have collected demographic information that could then be used to build very specific customer profiles. Because I did not collected this type of detailed personal information, the profiles I am building instead come from the codes that emerged during my analysis of my fieldwork notes; they will naturally contain a good deal of generalization, but my aim to establish these broader types that can be refined through further research. The most relevant characteristics for analysis were passersby's 
gender, age, and whether they viewed the window alone or with companions (and how many).

Gender's Impact on Response

I came to the field with some preconceived assumptions about some of the things I would see in regards to the gender of passersby. I suspected that women would be much more interested in the displays than men would, due to the higher degree of interest in fashion amongst women and the fact that women often take on the responsibility for buying Christmas gifts for their family and so are more receptive towards Christmas marketing. Despite the fact that men's fashion was sorely under-represented in the window displays, the number of men I saw stopping was only slightly less than the number of women I observed. Most of the men were older, middle-aged in appearance, and my suspicion is that they may have had women in their life (wives, daughters, etcetera) in mind as they were looking.

Women walking with other women were the most likely to interact with the windows, especially in regards to coming to a stop in front of them and talking to each other about the content. I noticed this on the very first day of my fieldwork, after just a few hours, and my initial assumption on this front was only strengthened over the following days. I have a few theories as to why groups of women are more likely to directly interact with the windows than other groupings or individuals. Due to the time of day and the location of the windows (the importance of which I will explore in more detail in a subsequent section), it is safe to assume that women walking with companions are likely out on leisure errands rather than walking by simply as a feature of a daily commute. One or multiple women in these groups were often carrying shopping bags, 
which suggests that the purpose of being in the area is to shop, thus making the displays a very viable topic of conversation. They may also be seeking out stimulation or entertainment, and their response to the window suggests that it has served its purpose in catching and capturing their attention. Furthermore, women also often solicit fashion opinions from one another. I know this to be true in my own life, and in my relationships with other women. Commenting on the windows to each other could be way of gauging their companions' opinions and weighing them against their own, or it could be a method through which one of the women demonstrates her fashion knowledge to the others as a way of exhibiting their knowledge.

What is interesting to me about the remarks that I observed women making to each other is the fact that they were rarely easily identifiable as being a positive or negative evaluation. With the exception of a few, like the woman who expressed a desire to own everything she saw, the comments tend to be more informative in nature, and often simply involve verbally pointing out different elements to one another. This was not necessarily true of the other groups that I observed. Mixed-gender groups, usually involving one heterosexual couple or several walking together, tended to stop for shorter periods of time. I assume this is due to reduced interest on the part of the male members of the group, although that assumption is likely informed by the stereotypical belief that men are less interested in fashion. It is worth mentioning, on this point, that the windows featured no representation of men's fashion. All of the mannequins were stereotypically female in form and were dressed in stereotypically female fashions. If 'male' mannequins had been part of the displays, perhaps men may have been more interested in them. The conversations that these groups had were very surface-level, and centered solely around 
the decorative elements of the windows. The monkeys in Window 7 (Figure 11), in particular, commonly came up in couples' discussions. It was also common to hear comments about elements that were common to all the windows - the monochromatic red palette, in particular. Sometimes they were even more general; in one instance, a man turned to his female companion as they passed by and simply remarked, "crazy, huh?"

With previous Saks holiday window displays in mind, these window displays contained a significant degree more shoppable merchandise than many in the past have. For instance, the 2017 holiday windows each featured only one mannequin, wearing a couture outfit that was not available for purchase. In comparison, the 2018 windows included clothing that was easily recognizable as designer (Burberry check scarves and logoed sweaters, for example), as well as various home goods, all of which was available for purchase within the store. The window labelled Window 9 (Figure 14) was one of the most engaging windows, and I credit this to the recognizability of the goods it contained. The mannequin closest to the glass was styled with a large scarf in the classic Burberry check pattern. In the space of an hour, this mannequin was photographed twice and indicated by a group of young women as their favorite. An older woman gave the mannequin a good look as she walked past and returned shortly after with a younger woman to give her instructions to purchase the items that mannequin was wearing. Because of this, the experience of viewing these windows was more akin to viewing a typical display — one that would be up any other time of year — than it was to viewing a holiday display. This may account for the number of men who stopped to examine the windows despite the lack of any elements that catered to them, as the windows functioned for them as a sort of gift guide. 


\section{Impact of Viewer's Age on Response}

My assumptions about how the age of viewers would impact their reception of the windows were based upon my assumptions about how different age categories interact with various types of visual displays. Since young adults and teenagers are more experienced with viewing media and shopping online, they may have a degree of interactivity with visuals that a physical window display does not provide. They are also less likely to have the level of disposable income that would make them a regular Saks Fifth Avenue shopper and so may be less interested in the displays. Ultimately, my fieldwork showed a similar degree of engagement across all age groups, although the reactions to and methods of engagement with the windows varied amongst the different demographics.

Groups of younger women seemed more likely to respond to the decorative elements of the window, rather than the fashion items. This may be because younger women do not yet have the earning power to buy designer items, and so they are limited in the ways that they can connect with the window displays. For example, Window 7 (Figure 11) included two small, red monkey statues, and a very large horse statue. Two subsequent groups of teenage girls both commented on the monkeys. In one of these groups, a girl said "my dad loves that" (indicating one of the monkeys), and in the following group one girl announced to her friends, "oh my god, I want that monkey." Comments from groups of older women included comments that were more targeted at the fashion elements. In one group of three, a woman announced to her friends that "[she wished she] could have everything in that display", referring to the clothing in window 8 -when they subsequently walked past window 7 , the same woman declared, "and 
there's all the accessories to go with it!" In mother and daughter pairings, which were relatively common, one party was almost always more interested than the other; rarely did they share the same level of enthusiasm for the displays.

\section{Impact of Group Composition on Response}

In general, people who walked past the windows alone were much less likely to engage with them. This is most likely due to the fact that these are the commuters, those who walk up and down Yonge Street daily as part of their regular routine. They either do not have the time to dedicate to window-watching, or they were simply so used to seeing the windows at the point of my observations that they were no longer worth giving any kind of specific attention.

People walking alone tended to engage with more of the windows, and for longer periods of time. Groups of people would often gather around one window, and then move on. Individuals would move from window to window, spending equal amounts of time at each. They were free from the obligation to consider the desires of traveling companions, and so could indulge their curiosity as much (or as little) as they chose. In almost every instance, this was a silent activity, so it is harder for me to gauge what these solo viewers thought of the windows. One way that individuals engaged with the windows that I did not observe with groups was photo-taking; it was surprisingly common amongst solo window-watchers for them to pull out their phones and take photos of not just one, but often multiple windows. One one occasion, a man pulled out a small digital camera and used that to take his photos. This kind of reaction is no doubt what the windows hoped to provoke; the use of visually jarring elements, like the monkey statues that continually caught everyone's eye, seems designed for quick documentation and subsequent sharing. 


\section{Engaging with Fashion Windows via Gestalt Theory}

As I have mentioned in the preceding sections, the level of engagement that I observed between passersby and the window displays was a good deal lower than I had predicted I would see. I believe this is due to the way that I thought about the windows, versus the way that the general public thought about the windows. I considered the displays to be a destination, something that I would make an effort to specifically go and see. My conception of holiday window displays is informed by the attitude that persists in cities such New York, where there is a long-standing tradition tradition of heading to stores such as Saks or Macy's specifically to see the Christmas windows. This kind of history does not yet exist in Toronto; the Saks location I observed opened in 2016, and so is very much in the infancy of its tenure in this city. Rather than being a destination, these window displays were more of an interruption in the travel of passersby, and were treated as such. The interactions, when present, were often abbreviated, and viewers often appeared to be visibly caught off-guard by the displays: they would walk past briskly, before registering what they had seen and backtracking to get a closer look. Because most viewers had not come with the specific intention to look at the displays, they were either unwilling or unable to give them devoted time and attention.

During my first shift, standing on the sidewalk, I had to decide what kind of activity I should consider as engaging with the displays. I was alarmed by the fact that most people were quickly walking past the windows, and I was very eager (one may even venture to say desperate) to collect a lot of data, to legitimize my choice to be out there if nothing else. As a result, the notes from my first fieldwork shift include the recording of even the most passing glances at the windows. I eventually realized that this wasn't 
necessarily valuable, as it mostly resulted in frantic note-taking rather than more detailed observations, and there was also the chance that these passing glances were not even intended to take in the displays - it is just as likely that those viewers were simply quickly observing their own reflection. I decided after that first day to only record the actions of those who appeared to be going out of their way in some regard to observe the displays: noticeably slowing their walking speed, coming to a complete stop, discussing with a companion or companions, or taking photographs.

These different methods of engagement naturally result in different experiences of the window, due to the differing degree of visual information that is absorbed in each instance. If the viewer slows their pace in order to look at the display, but does not stop, their view of the scene is in perpetual motion. Each step brings a different part of the display into closer view. These individuals are usually walking on the window side of the sidewalk, as well, which means that they do not have the vantage point to see with window fully and are instead seeing only smaller sections in series. This is also true of the individuals and groups who came to a halt completely in order to observe the display. They are able to get a clearer picture, so to speak, than those who chose not to stop; however, they are subject to the same spatial limitations. The imprint that the windows left on these groups may also be impacted by any conversation or discussion that they participated in. An initially favourable evaluation could be reversed by a negative comment from a companion, for example, or they may point out an element of the window that their partner did not initially see themselves and may not have thought to look at had they been walking alone. 
The act of photographing the windows has interesting implications for gestalt theory as a tool for viewing. Those who choose to take a photo of the windows usually do not spend much time observing them in the moment. The pattern of behavior that I generally observed went as follows: the individual would look at the window, spend a few moments observing, and then take their smartphone out where they stood to capture a photograph before moving on. Deviations from this include one young woman who made an effort to capture a display from several different angles, and a few individuals who stepped to the edge of the sidewalk to get a wider shot. In all of these instances, the threedimensional space of the window is compressed into a two-dimensional image. The effectiveness of "good gestalt" in design is evaluated differently in three dimensions as opposed to two - a design choice that looks impressive when viewed in-person might not come across as well, or at all, in a photograph. Photographing the windows also removes them from the environmental context, which contains a multitude of visual and physical cues that influence the viewing experience. Because I chose not to include an interview component in this project, I am left questioning what the purpose of the photographs were, and how the individuals who took the photos ended up using them, if at all.

Gestalt theory was initially conceived to describe the tendency on the part of humans to organize visual stimulus according to a certain higher logic that seeks to maintain order. The phenomena of gestalt explains why, without intentional organization effort on the viewer's part, one sees constellations instead of individual stars (Kohler, 1947). Because it is explain an unconscious impulse, gestalt applies primarily to acts of 'everyday' seeing, rather than in instances of focused viewing. Those scenarios involve different processes and conventions. For instance, a person observing a painting in the 
context of the art gallery is engaged in thoughtful, focused viewing, which engages processes beyond those that are explained by gestalt theory. However, window displays occupy a type of liminal space between everyday viewing and this focused gaze, due to their physical locations in the backdrop of everyday life. The manner by which most viewers come upon them results in a more unconscious sort of viewing. As experienced art objects, or perceptually presented artworks, they occupy unique territory (Koffka, 1940).

The "success" or degree visual interest generated by a window display depends upon the way it takes experienced objects-items which have a use value that is known to us (Kohler, 1947) - and displays them in ways that either align with this expected use value, or defy it. Gestalt theory attempts to define the way that we give objects meaning by suggesting that we arrive at these conclusions via an object's, or visual unit's, association with the viewer and other nearby objects/units. It is the position of a unit within a whole, whether that be a visual plane or an experience, that determines its meaning (Ellis, 1930). The Saks windows contain objects that align with expectations: for example, they feature clothing on mannequins, which present the clothes in the way that we are most accustomed to seeing them and also fits with the expectation of what would be in the window of a department store. Placing these objects in proximity with those that we would never expect to occupy the same visual plane, but have encountered in other environments (for example, a red horse) prevents the displays from falling into a expected set of organized objects and provokes further investigation. On another level, their positioning as visual units and the way that they are organized by the brain upon viewing also dictate the viewing experience. This can be seen in the way that the 
suitcases are stacked in window 8 (Figure 12) or the uniform height of all of the elements in window 5 (Figure 9).

In the case of the windows examined here, viewer's assumptions and internal logic for viewing a window display also must be taken into account. Because of the often spectacular nature of Christmas window displays, I suspect that there is also a summary evaluation of experiences that informed the viewer's response to these windows (Ariely $\&$ Carmon, 2000). These summary evaluations can create anticipation of an event before it even occurs. The 2018 Saks Fifth Avenue windows are a departure from the traditional style of Christmas window display in that they contain no overt holiday connections; even the colour red, used to great excess, loses a good deal of its associative power when it is not accompanied by the traditional shade of Christmas green. There is also a lack of any of the symbols that are traditionally associated with Christmas, or even stereotypical winter imagery. There is little to tie these windows to the time of year at which they are being displayed, and this lack of alignment with viewer's summary evaluations may explain what I interpreted as a generally lukewarm response to the windows.

\section{Concluding Thoughts}

My fieldwork, and the subsequent analysis, are a product of my specific experiences of a specific set of display windows at a specific place and time. While the analysis may not provide a generalized result that is immediately applicable to other scenarios, I believe it does present a case for the value of further ethnographic research in this field. Experiencing the windows first-hand, and including an account of this experience, allows one to really get at which design choices are the most effective, or impactful. In the case of this project, experiencing the windows first-hand was essential 
in determining how gestalt theory could help me understand my own viewing experience so that I could then attempt to extrapolate that understanding to the viewing experience of others, without having to ask them to explain it in their own words. 


\section{CHAPTER FIVE: CONCLUSION}

\section{Summary of Conceptual and Methodological Frameworks}

Several frameworks were key in analyzing the findings of my fieldwork. Gestalt theory was employed to illustrate how window displays, particularly in the fashion industry, borrow techniques from and can be analyzed in the same way as twodimensional designs. By analyzing specific fashion windows, I have shown how the principles of gestalt design change when they are implemented in a three-dimensional space. The psychological applications of gestalt were also used as a method of measuring and evaluating experiences as proposed by Ariely \& Carmon (2002). Gestalt informed both my own evaluation of the window displays and my analysis of how others may have evaluated them. In my analysis I have shown how the window's contents, the physical space surrounding them, and larger symbolic constructs such as Christmas come together to inform the viewing experience.

Martineau's concept of affective qualities and retail personality were also highly relevant are accomplished by way of applying gestalt to a commercial space; this theory informed the portion of the analysis that focused on the environment created outside of the Saks Fifth Avenue and Hudson's Bay stores. Including the exterior surface and space around the building is the next logical extension of Martineau's theory, which was more preoccupied with the interior space of retail environments. His writings also make use of gestalt theory without referencing them directly, which reinforces the potential for a relationship between this type of theory and retail environments.

The methodology for this project was informed by the anthropological tradition of ethnography. More specifically, I employed an autoethnographic research design, which 
encourages an emphasis on reflection on the researcher's part as a method of analyzing a phenomenon or culture in which they participate. In this instance, I both analyzed my feelings and assumptions towards the window displays and observed the reactions of other viewers. My intentions for this project were to begin to explore a side of window display that has not yet been paid much attention in academic research, so this more exploratory research design was well-suited.

\section{Contributions to the Field}

The intention of this research project was primarily to draw attention to a lack of conceptual research on the topic of window displays. I feel that it was successful in this regard. What this project has hopefully demonstrated is that window displays are very rich sites of potential analysis, beyond the quantitative methods that have typically been applied. The creative process behind their production, the context of their location, and the degree of interaction with the public are just a few of the characteristics of window displays that lend themselves well to a more conceptual form of analysis, using theories from the social sciences and humanities. These characteristics were examined in this research project, but there are no doubt more to be explored. This is an argument in favour of continuing to develop this currently-sparse body of research.

This project has made contributions towards gestalt research, as well. To date, gestalt has found some limited applications outside of its roots in psychology-it is often used as a teaching tool in two-dimensional graphic design. This project stretched its design applications to successfully cover three-dimensional art environments. Gestalt theory has been used as a method of inquiry by a few researchers prior to this project, 
most notably by interaction gestalt research. This project is another entry into this emerging field. What this project has provided for the field of anthropological, and more specifically ethnographic research, is the embracing of commercial environments as cultural sites that are worthy of a more personal and involved research design. It also suggests that ethnography can be a worthwhile method for more exploratory research, rather than the established procedure of developing theory before heading into the field and seeking to find supporting evidence.

Because the results of the MRP are empirical in nature, it is more difficult to cite potential industry implications. Finding applications in industry is the motivation behind most contemporary window display research, much of which seeks out actionable data and statistics. This project is a break from that, and as such has primarily academic contributions to offer. With that being said, there are some general takeaways that could have value in industry applications. Chief amongst these are the observations of the different behavior that was encouraged by the physical space in front of the window, as this is an area that is often neglected in any study about window displays. The findings of this project suggest that the space surrounding the window is just as important to consider as the space within.

\section{Implications for Future Research}

This project is intended as an initial exploratory effort towards broadening several research fields. The research design was somewhat experimental in nature, and as a result, there are several changes I would propose making if I or another researcher were to carry out this project again, as well as different variables that I would suggest 
exploring in order to take the research further. Firstly, I collected a fairly limited amount of ethnographic data. I feel that it was more than sufficient in forming the basis of my analysis, and it was effective in illustrating a different method of collecting ethnographic data. However, it would be interesting to see what would result from a traditional ethnographic research design applied to the same subject. This could be limited to the same parameters as my initial design—a shorter timeframe and a small research site—but expanded to include ethics approval for interviews, for example. It could also be extended to a much longer, multi-site survey that includes window displays from multiple retailers. Including interviews with window dressers and the creative teams behind the windows would also be a worthwhile addition; there are few opportunities to have a designer's vision and the public's reaction to it analyzed within the same text.

What I would do to follow this project is carry out more smaller-scale ethnographic studies in different environments in order to develop a larger body of data to compare and contrast. I would maintain the same research site, at Saks Fifth Avenue, but would extend it slightly to encompass the Hudson's Bay windows as well. While there are other luxury shopping areas in Toronto with impressive windows, many of them are located in more isolated, purpose-built spaces. Saks and HBC's location within the busy core of downtown Toronto ensures that they are exposed to a much wider range of people, which makes them much more valuable as sites for human-focused research. Limiting my research to the same site also makes it possible to directly compare my findings from each period.

Comparing the reactions from 2018's holiday windows to 2019's holiday windows would be a good place to start, as overheard conversations from the fieldwork 
notes suggest that some viewers make these comparisons on their own. Involving the Hudson's Bay windows from the beginning of the fieldwork period and splitting the observation time evenly between the two is an adjustment that I would make. For this project, I initially did not intend to observe the Hudson's Bay windows, as they did not include any merchandise that I felt could be fairly classified as 'fashion'. However, my very limited observation of the windows towards the conclusion of the fieldwork proved that they provided a wealth of information for contextualizing the Saks windows, and I realized that the relationship between the two was stronger than I had initially assumed. While the comparison would not be as direct, including window displays themed for other holidays would be another potential step. This would allow for fieldwork in different conditions, which could impact the findings. For example, during the summer months, there may be more people walking past the windows as more people choose to commute on foot rather than in a vehicle. 


\section{BIBLIOGRAPHY}

About Broadway Cares/Equity Fights AIDS | Broadway Cares. (n.d.). Retrieved from https://broadwaycares.org/about-broadway-cares-equity-fights-aids/

Allen, E. (2014, December 15). Highlighting the Holidays: Window Dressing. Retrieved February 4, 2019, from https://blogs.loc.gov/loc/2014/12/highlighting-theholidays-window-dressing/

Anderson, L. (2006). Analytic Autoethnography. Journal of Contemporary Ethnography, 35(4), 373-395.

Arnheim, R. (1988). The Power of the Center: A Theory of Composition in the Visual Arts. Los Angeles: University of California Press.

Ariely, D., \& Carmon, Z. (2000). Gestalt Characteristics of Experiences: The Defining Features of Summarized Events. Journal of Behavioral Decision Making, 13(2), 191-201.

Atwal, G., \& Williams, A. (2009). Luxury Brand Marketing - The Experience is Everything! Journal of Brand Management, 16, 338-346

Ballard, E. G. (1976). The Nature of the Object as Experienced. Research in Phenomenology, 6(1), 105-138.

Barthes, R. (1972). Mythologies: Roland Barthes. New York: Hill and Wang.

Baum, L. F. (1897, November 1). The Window Gazer. The Show Window, 1(1).

Beatty, S. E., \& Smith, S. M. (1987). External Search Effort: An Investigation Across Several Product Categories. Journal of Consumer Research, 14(1), 83.

Behrens, R. R. (1998). Art, Design, and Gestalt Theory. Leonardo, 31(4), 299-303.

Bernard, H. R. (2002). Research Methods in Anthropology: Qualitative and Quantitative approaches (3rd ed.). Walnut Creek, CA: Altamira Press. 
Biehl-Missal, B. (2012). The Atmosphere of the Image: An Aesthetic Concept for Visual Analysis. Consumption Markets \& Culture, 16(4), 356-367.

doi:10.1080/10253866.2012.668369

Böhme, G. (2018). Atmospheric Architectures: The Aesthetics of Felt Spaces (A. EngelsSchwarzpaul, Ed.). London: Bloomsbury Visual Arts.

Christmas Toys [Photograph]. (1908-1917). George Grantham Bain Collection, Library of Congress, Washington, D.C.

Crowley, A. E. (1993). The Two-Dimensional Impact of Color on Shopping. Marketing Letters, 4(1), 59-69.

Dennis, C., \& King, T. (2007). Special Issue: Social and Experiential Retailing Part 1 and 2. International Journal of Retail and Distribution Management, 35(6-7), 421611.

Doonan, S. (1998). Confessions of a Window Dresser: Tales From a Life in Fashion. New York: Penguin Studio.

Ellis, W. D. (1930). Gestalt Psychology and Meaning. Berkeley, CA, US: Sather Gate Book Shop

Emerson, R. M., Fretz, R. I., Shaw, L. L. (1995), Writing Ethnographic Fieldnotes. Chicago: University of Chicago Press.

Ezzy, D. (2002). Qualitative Analysis: Practice and Innovation. London: Routledge.

Fionda, A. M., \& Moore, C. M. (2009). The Anatomy of the Luxury Fashion Brand. Journal of Brand Management, 16, 347-363.

Glaser, B. G., \& Strauss, A. (1967). The Discovery of Grounded Theory: Strategies for Qualitative Research. New York: Aldine Publishing.

Hayano, D. M. (1982). Poker Faces: The Life and Work of Professional Card Players. Berkeley: University of California Press.

Klokis, H. (1986). Store Windows: Dynamic First Impressions. Chain Store Executive, 62, 108-109. 
Köhler, W. (1947). Gestalt psychology; An Introduction to New Concepts in Modern Psychology (Rev. ed.). Oxford, England: Liveright.

Koffka, K (1940). Problems in the Psychology of Art. In Richard Bernheimer (ed.), Art: A Bryn Mawr Symposium. New York: Oriole Editions. 180-273

Kopun, F. (2016) “Toronto's Saks Fifth Avenue - A First Look.” Thestar.com, Toronto Star, 16 Feb. 2016, www.thestar.com/business/2016/02/16/torontos-saks-fifthavenue--its-almost-ready.html.

Lange, F., Rosengren, S., \& Blom, A. (2016). Store-Window Creativity's Impact On Shopper Behaviour. Journal of Business Research, 69(3), 1014-1021.

Layder, D. (1998). Sociological Practice: Linking Theory and Research. London: Sage.

Laverie, Debra A., Kleine, R., \& Kleine, S. (2002) Reexamination and Extension of Kleine, Kleine, and Kernans Social Identity Model of Mundane Consumption: The Mediating Role of the Appraisal Process. Journal of Consumer Research, (28)4, 659-669.

Lim, Y., Stolterman, E., Jung, H., \& Donaldson, J. (2007). Interaction Gestalt and the Design of Aesthetic Interactions. Proceedings of the 2007 Conference on Designing Pleasurable Products and Interfaces.

Lofland, J., Snow, D., Anderson, L. \& Lofland, L. H. (2006), Analyzing Social Settings: A Guide to Qualitative Observation and Analysis (4th ed.). Belmont CA: Thomson Wadsworth.

Martineau, P (1958). The Personality of the Retail Store. Retailing: Critical Concepts, edited by Anne M Findlay and Leigh Sparks, vol. 3, Routledge, 2002, pp. 98-112.

Miles, M. B., \& Huberman, A. M. (1994). Qualitative Data Analysis (2nd ed.) Thousand Oaks, CA: Sage.

Moore, P. \& Fitz, C. (1993) Gestalt Theory and Instructional Design. Journal of Technical Writing and Communication, (23)2, 137-157.

Nicosia, F. M., \& Mayer, R.N. Toward a Sociology of Consumption. Journal of Consumer Research, (3)2, 65-75. 
Oh, H., \& Petrie, J. (2012). How do Storefront Window Displays Influence Entering Decisions of Clothing Stores? Journal of Retailing and Consumer Services, 19(1), 27-35.

Opriş, M, \& Brătucu, G. (2013) Visual Merchandising Window Display. Bulletin of the Transilvania University of Braşov, (6)55, 51-56.

Park, C. Whan, Jaworski, B., \& McInnis, D. "Strategic Brand Concept-Image Management.” Journal of Marketing, 50(4), 135-145.

Pegler, M. M., \& Corrons, A. (2011). Store Windows. New York, NY: RSD Publishing.

Pegler, M. M. (1994). Store Windows That Sell. New York: Retail Reporting.

Pine, B., II, \& Gilmore, J. H. (1998). Welcome to the Experience Economy. Harvard Business Review, 97-105.

Rothman, R., \& Verstegen, I. (2007). Arnheim's Lesson: Cubism, Collage, and Gestalt Psychology. Journal of Aesthetics and Art Criticism, 65(3), 287-298.

Russel, B. H. (2002). Research Methods in Anthropology: Qualitative and Quantitative Approaches. Walnut Creek: AltaMira.

Saldaña, J. (2015). The Coding Manual for Qualitative Researchers. Los Angeles: SAGE.

Santayana, G. (2012). Objectified Experience and the Sense of Freedom. New England Review, 33(3), 181-183.

Schneier, M. (2018, November 21). Why Holiday Windows Still Matter. Retrieved from https://www.nytimes.com/2018/11/21/style/holiday-department-storewindows.html

Seidman, I. (2006), Interviewing as Qualitative Research: A Guide for Researchers in Education and The Social Sciences (3rd ed.). New York: Teachers College Press.

Sen, S., Block, L. G., \& Chandran, S. (2002). Window Displays and Consumer Shopping Decisions. Journal of Retailing and Consumer Services, 9(5), 277-290. 
Sirgy, M. Joseph. (1982) Self-Concept in Consumer Behavior: A Critical Review. Journal of Consumer Research, (9)3, 287-300.

Suhrawardi, R. "Eckhaus Latta: Possessed, The First Fashion Exhibition At The Whitney In Over 20 Years." Forbes, Forbes Magazine, 6 Aug. 2018, www.forbes.com/sites/rebeccasuhrawardi/2018/08/05/eckhaus-latta-possessedthe-first-fashion-exhibition-at-the-whitney-in-over-20-years/\#275b4c41584c.

Twyman, R.W. (1954) History of Marshall Field \& Co. University of Pennsylvania Press.

Vallance, E. (2009). Exploring Visual Culture Downtown: Shop Windows as Still Life. Visual Arts Research, 35(1), 35-49.

THE RED RIBBON. (n.d.). Retrieved from http://www.worldaidsday.org/the-red-ribbon/

Thorstein Veblen, The Theory of the Leisure Class: An Economic Study of Institutions (New York: B. W. Huebsch, 1918).

Van Maanen, J. (1988). Tales of the Field: On Writing Ethnography. Chicago: University of Chicago Press.

Van Maanen, J. (1990). Researching Lived Experience: Human Science for an Action Sensitive Pedagogy. Albany, NY: SUNY Press.

Verstegen, I. (2005). Arnheim, Gestalt, and Art: A Psychological Theory. Wien: Springer.

Wertheimer, M. (1938). Gestalt Theory. A Source Book of Gestalt Psychology. Ed. Willis D. Ellis. New York: Harcourt, 1938. 1-11.

Wertheimer, M. (1939). Laws of Organization in Perceptual Forms. In W. D. Ellis (Ed.), A Source Book of Gestalt Psychology. 71-88. London: Kegan Paul, Trench, Trubner \& Company.

Wong, B. (2010). Gestalt Principles (Part 1). Nature Methods, 7(11), 863.

Wong, B. (2010). Gestalt Principles (Part 2). Nature Methods, 7(12), 941. 
